\title{
IG \\ pP \\ NORK \\ The Causal Effects of Adolescent School Bullying Victimisation on Later Life Outcomes
}

Emma Gorman

Colm Harmon

Silvia Mendolia

Anita Staneva

Ian Walker

Working Paper

2019-019

03/2019 


\title{
The Causal Effects of Adolescent School Bullying Victimisation on Later Life Outcomes
}

\author{
Emma Gorman \\ Lancaster University Management School and IZA, Bonn \\ Colm Harmon \\ University of Sydney and IZA, Bonn \\ Silvia Mendolia \\ University of Wollongong and IZA, Bonn \\ Anita Staneva \\ University of Sydney \\ lan Walker \\ Lancaster University Management School and IZA, Bonn
}

This version: March $20^{\text {th }}, 2019$

Keywords: bullying, victimization, long term outcomes

JEL codes: I21, 124, I26, J24

\begin{abstract}
We use rich data on a cohort of English adolescents to analyse the long-term effects of experiencing bullying victimisation in junior high school. The data contain selfreports of five types of bullying and their frequency, for three waves of the data, when the pupils were aged 13 to 16 years. Using a variety of estimation strategies - least squares, matching, inverse probability weighting, and instrumental variables - we assess the effects of bullying victimisation on short- and long-term outcomes, including educational achievements, earnings, and mental ill-health at age 25 years. We handle potential measurement error in the child self-reports of bullying type and frequency by instrumenting with corresponding parental cross-reports. Using a detailed longitudinal survey linked to administrative data, we control for many of the determinants of bullying victimisation and child outcomes identified in previous literature, paired with comprehensive sensitivity analyses to assess the potential role of unobserved variables. The pattern of results strongly suggests that there are important long run effects on victims - stronger than correlation analysis would otherwise suggest. In particular, we find that both type of bullying and its intensity matters for long run outcomes.
\end{abstract}

Acknowledgements: We are grateful to our respective institutions for providing support to facilitate our collaboration. The UK Economic and Social Research Council funded Gorman and Walker's wider project on the long-term legacy of school choice. Harmon and Staneva's contribution was supported by the Australian Research Council through a Discovery Program Grant (DP140102491), and the Centre of Excellence for Children and Families over the Life Course (CE140100027). The data was provided via the secure server at the UK DataService and is available to other researchers subject to registration and training. The authors can provide their STATA code and advice to facilitate replication and extensions to our work.

Corresponding author: Professor lan Walker, Department of Economics, Lancaster University Management School, Lancaster LA1 4YX, UK. Email: ian.walker@lancaster.ac.uk 


\section{Introduction}

Bullying at school is thought to be a widespread phenomenon that harms many children. ${ }^{1,2}$ Yet there is relatively little quantitative research into the wider and longterm effects of having been bullied as a child—most studies concentrate on short term educational outcomes alone. Moreover, very little research has explored the implications of the intensity (frequency) of bullying, within and across school years. Much of the literature explores the effects of being bullied at a point in time, and only on proximate outcomes. Nor has the literature discriminated between types of bullying to facilitate an investigation into their differing impacts on outcomes. Moreover, despite the high prevalence of bullying, there is little existing research that deals with non-random selection into being a victim of bullying.

The contribution of this paper is that it explores the long-term impacts of a variety of types of bullying, of varying intensity, over several years, separately for boys and girls, and explores the selectivity issue. We use a rich cohort study of English children, and while we focus on methods that deal with selection on observable we also attempt to tease out causal effects that allow for selection on unobservables. We marshal a number of empirical methodologies to attempt to identify the causal effects of this wide variety of "treatments" on a range of age-25 (and earlier) "outcomes" that are recorded in our data. Specifically, we analyse the following labour market and education outcomes: Advanced (A) level educational qualifications (usually taken at the end of senior high school at the age of 18) and A-level points score ${ }^{3}$; GCSE qualifications (usually taken at 16 at the end of compulsory schooling); having a university degree; attending an elite HE institution; dropping out of HE; degree classification; log earnings; unemployment; and a mental (ill-) health index.

\footnotetext{
${ }^{1}$ Throughout we refer to victimisation through bullying at school simply as bullying. Moreover, bullying in this paper is wholly school based - we do not consider, for example, workforce bullying.

${ }^{2}$ The 2017 edition of the Annual Bullying Survey, a large on-line non-random 'snowball' survey of young people in secondary schools and colleges across the UK, records $54 \%$ of all respondents had been bullied at some point in their lives. According to this survey, one-third of all victims experience social anxiety, one-third experience depression, and a quarter of the victims had suicidal thoughts.

${ }^{3}$ Usually in three or four relatively narrow subjects that were selected at age 16 and studied over a twoyear period in senior high school. The grade results from these examinations are used as the primary admission criterion by universities and are often collapsed to a single A-level points score for this purpose.
} 
Quantifying the effects of bullying is important. There have been many schoolbased anti-bullying programs that, Tofi and Farrington (2011) suggest, bring about significant reductions in bullying incidence. ${ }^{4}$ This work provides estimates of the potential benefits of bullying reduction to put alongside the costs of such policies. Moreover, we highlight the differences in the effects by bullying type - evidence that may support a redistribution of resources towards tackling particularly harmful types.

We regard our primary contributions to be twofold: we address both the endogeneity arising from both selection on unobservables and potential measurement error in the various forms of victimization that are self-reported in the data. We confront the potential endogeneity problem by adjusting for key determinants of both bullying and child outcomes, via our rich data on both survey and administrative data. This is complemented by a comprehensive range of sensitivity analyses: falsification/placebo tests, and an assessment of the robustness of effects to specific deviations from the conditional independence assumption. To handle potential measurement error in the child's self-reports of bullying victimisation frequency, we use the detailed parental cross-reports of bullying. Both youths and parents answered whether the individual was a victim of each of five forms of bullying in the last 12 months. Moreover, both the child and the main parent are asked about the frequency of victimization. We use the parental cross-reports of bullying as an instrumental variable to resolve potential measurement error arising from self-reported bullying (an approach which has a long history, in, for example, analyses of twins). ${ }^{5}$ Here our IV estimates rely on the identification assumption that cross-reported bullying at ages 14-16 does not affect own outcomes at 25 except through its correlation with self-reported bullying at 14-16. As usual, it is not possible to test this instrument validity assumption but we do conduct a number of robustness checks.

Secondly, we examine the heterogeneous effects of varying types and intensities of bullying. Previous literature has typically relied on a simple binary treatment as a measure of bullying victimisation, and we build on this by using more detailed

\footnotetext{
${ }^{4}$ For example, the influential Olweus Bullying Prevention Program aims to provide structured classroom discussions to discourage bullying and to reward helpful behavior, and has been positively evaluated, See Olweus (2013) for England. For Norway, the USA, and elsewhere see http://www.violencepreventionworks.org/public/olweus_history.page.

${ }^{5}$ See Ashenfelter and Rouse (1998). Light and Flores-Lagunes (2006) explores the use of cross-reports in the context of non-classical measurement error. Bingley and Martinello (2017) appears to be the only validation study of self-reports that considers the case where the cross-report is also measured with error.
} 
treatments. To do this, we first use factor analysis to create a summary variable capturing the richness of the variation in the type and frequency data; and second, we construct a multi-valued categorical treatment, which allows the effects of bullying to differ by type and intensity. In terms of estimation, we use least squares to adjust for observable factors, to reduce the potential confounding role of selection on unobserved variables and extend this to linear IV to incorporate our parental cross-report instrument. Our motivation in employing IV is to address potential measurement error in the self-reported bullying measures. We also use matching and weighting methods to reduce any effects of functional form assumptions - employing propensity score matching (PSM) where we consider a single discrete treatment, and inverse probability weighted regression analysis (IPWRA) where we consider multiple treatments. The IPWRA analysis of treatments also facilitates the estimation of the effects of different types and intensities. The least squares, matching and weighting methods also avoid the local treatment effect heterogeneity, which arises in many IV settings. In our setting, we have data on many of the determinants of bullying identified in the previous literature, and we build a credible case for a selection on observed variables assumption. However, we recognise that bias from unobserved variable may remain a concern, and we examine the potential for unobserved variables to affect the estimates using recently developed tests that consider both the stability of the coefficient(s) of interest in the face of increasing the set of control variables, and the change in $R^{2}$ across specifications (see Oster, 2017; Krauth, 2016). In the context of matching, we use a similar test due to Nanninci (2007) and Ichino et. al. (2008).

We report a mosaic of results reflecting the range of possible definitions of the treatments, estimation methods, and control variables. Together, the results suggest that there are important long run effects of bullying victimisation-stronger than simple correlations analysis would suggest.

The rest of the paper is organized as follows. Section 2 describes the education system and the treatment of bullying. Section 3 briefly focusses on the key papers in the subset of literature that also attempt to provide causal estimates. Section 4 describes the data and the construction of the bullying intensity measure. Section 5 discusses the estimation methodologies. Section 6 presents the main results and our evaluation of them. Finally, Section 7 offers some reservations, concluding comments, and suggestions for further work. 


\section{Educational Context}

Compulsory schooling in England starts at age four to five: children are expected to be attending full-time schooling at the age of five and are admitted each September to a "Primary" school before they reach that age. At age 11 (Year Six) there is usually a transition to "secondary" school for a further five years of study, although in some areas there is an intermediate stage of schooling provided by "middle schools" that cover 11 to 13 . The end of compulsory schooling is now somewhat blurred with children being expected to continue in school (usually in secondary schools from 16 to 18 often in the same location/campus as earlier schooling occurred, but sometimes in a "Sixth Form" college that admits children from nearby secondary schools for further study). Further Education colleges offer an alternative route to vocational training up to age 18; and all those in work from age 16 are expected to combine this with at least 20 hours of training per week that may be based in a FE college or in the workplace (Harmon, 2017). There is often an element of selection by ability, based on earlier attainment, in admission to post-compulsory schools and sixth form colleges.

There is a common curriculum across almost all English schools which is organized into 'Key Stages' with KS1 being up to age seven, KS2 being from ages eight to $10, \mathrm{KS} 3$ being ages 11-13, and KS4 being ages 14-16. There are low stakes tests at the end of each KS1-3. At the end of KS4 at the age 16, students take the highstakes General Certificate of Secondary Education examinations (GCSEs). Students are usually examined in between five and ten subjects, and usually need to attain passing grades (A, B, C) in at least five of them, including Mathematics and English, in order to be tracked into further academic study in senior high school. After their GCSEs, students may decide to pursue further studies from age 16 to 18 , typically in just three or four subjects for study at Advanced (A) level, depending on their academic preferences and intentions toward higher education. Higher Education (HE) admission is driven largely by A-level results that are graded A to E and grades are often converted into a cardinal scale by assigning points to grades.

The overwhelming majority of children attend publicly-funded secondary schools which admit children based on parental preferences and ration places at the margin, usually according to proximity, if capacity constraints bind. These include “community" schools that are managed by their Local Education Authorities, although that funding is provided under complex arrangements that involve central and local 
governments - and these arrangements are currently evolving into a national funding formula which allows for high need schools. Approximately $6 \%$ of children attend private schools, which usually have charitable status and operate on a not-for-profit basis. They can admit by ability and can charge fees. Home schooling is rare in England (current estimates suggest less than $0.5 \%$ ), whilst a small proportion of secondary school children (less than 5\%) attend academically selective publicly-funded (Grammar) schooling (a reduction from around 20\% of much earlier cohorts-see Harmon and Walker, 2000). There are also publicly-funded schools that use religious background as an admission requirement. Finally, there are an increasing number other publicly-funded schools, known as Free Schools and Academies, that are similar to US Charter Schools in having a degree of autonomy from local government, are funded largely from central government, but are different in that both types operate on a nonprofit basis. ${ }^{6}$ For a broad discussion of the issues of school choice and type see Burgess et al. (2015).

In the UK, the policy approach to bullying has not been prescriptive. A range of resources are made available for the school leadership, allowing the school to choose the most appropriate as opposed to the more formal processes seen in other countries. Thompson and Smith (2010) provide a detailed overview with selection of case study schools that showed good practice in their anti-bullying work. Among the successful practices in the UK, the authors listed some proactive, peer support (peer listening and buddy schemes from transition; peer mediators trained in restorative approaches and play grounders), Head Teacher/School Principal 'open door' policy for parents and children, positive play sessions and safety haven designated spaces, home visits, reactive and restorative strategies (see Thompson and Smith (2010) and Smith and Thompson (2014) for an overview). The Department of Education (DfE) has, from 2014, required schools to implement an effective anti-bullying strategy by adopting anti-bullying policies with clear definitions and procedures that are communicated to the whole school community (see Department of Education, 2017).

\footnotetext{
${ }^{6}$ Free Schools and often belong to chains of similarly branded schools and are effectively new entrants to the sector. Many former community schools have converted to gain Academy status. Many have a faith focus to them. Academy status was originally given to failing secondary schools, in an attempt to turn them around, but this status has been increasingly given to successful secondary schools who are often then required to assist in the management and operations of nearby weaker schools.
} 
In addition to investigating educational achievement at school, we also conside the effects on longer term outcomes - at HE and in work. HE is usually pursued from age 18 at over 150 Higher Education Institutions (HEIs), some very small and specialised, which are collectively referred to as universities. Higher education participation rates are over $40 \%$ of the cohort and this has grown dramatically in the last three decades. Course fees have been dramatically increased (and public funding almost eliminated) since 2010 but there is now a comprehensive, sophisticated, and highly subsidized, student loan program that supports access, especially for low parental income students. Take-up of these loans is high and repayments are income contingent with the balance after 30 years being written off. As a result, demand for university is relatively inelastic to price, and there is little evidence that fees have resulted in any fall in participation - either overall or for low SES students (see Murphy et al, 2017). Dropping-out is relatively scarce (around 8\% across the sector). Although England is geographically small, and so proximity to a university is much higher than in most other countries, the majority of students move away from their parental homes to study HE, and most of those that do will form (or join) households elsewhere when they graduate and start work. Finally, with respect to HE attainment, HEIs in England, (and Wales and Northern Ireland) offer undergraduate courses that are typically 3 years duration, studied mostly on a full-time basis and mostly straight from senior high school. Courses are usually specialized where a single narrow major is often pursued exclusively. Unlike the US, UK undergraduate professional courses such as law, medicine, and management are available across most HEIs.

\section{Existing Bullying Literature}

Bullying has been recognised as a major public health problem in developed countries (Klomek et al., 2010). OECD (2017) contains a brief comparison of PISA science scores across countries by the prevalence of bullying across schools ${ }^{7}$. Surprisingly the effect on scores in Britain, controlling for school fixed effects, is ranked amongst

\footnotetext{
${ }^{7}$ Little comparative work across countries about school bullying and its effects exists. Apart from OECD (2017), Due et al (2005) applied the same survey instrument to 123,227 students (age 11, 13 and 15) from a nationally representative sample of schools in 28 European and North American countries in 1997-98. There was widespread agreement across all countries that the health effects were negative and serious. Ammermueller (2012) uses a dataset of all students from classes in particular grades in randomly selected schools in the TIMMS project from 11 European countries. The author studies the effect of personally experiencing being physically hurt or experiencing theft at school and so is focused on severe bullying.
} 
Scandinavian countries and is far below most Wester European countries. Thus, our results here may have even greater relevance elsewhere in the world.

There are many papers that address bullying, but we do not conduct a broad review of qualitative or non-causal studies and focus mostly on the very small literature that purport to attempt to estimate causal effects. In Table 1 we attempt to interpret the effect sizes from these studies in a comparable way. Reviews of the work on bullying in the education and psychological literature can be found for example, in Sharp (1995), Ladd et al. (2017), Bond et al (2001), Due et al (2005), Arseneault et al (2010), Ford et al., (2017), Woods and Wolke (2004). Victims of frequent bullying have reported a range of psychological, psychosomatic and behavior problems including anxiety and depression, low self-esteem, mental health problems, sleeping difficulties, sadness, and frequent pain.

There is a relative paucity of economics research on bullying. The most relevant study to this work is Eriksen et al. (2014) which uses large surveys of Danish parents and teachers that record bullying prevalence and severity and combines this with outcomes from Danish administrative data on $9^{\text {th }}$ grade (at age 16 in Denmark) based on tests in language and mathematics skills. Some $27 \%$ of the estimation sample record being bullied (to any extent), with $20 \%$ of those bullied reporting severe bullying. They estimate the relationship between bullying and future outcomes through an identification strategy based on classroom peer effects, assuming that the proportion of children whose parents had criminal backgrounds changes other life outcomes only through their effect on bullying by other children. ${ }^{8}$

The authors report an OLS estimate of -0.14 of a standard deviation of the grade point average (GPA) from bullying but find that bullied children have very much lower academic achievement in $9^{\text {th }}$ grade in their IV results, although these results are noisy. Their results are robust to exclusion of individuals with no classmate parents convicted of crimes $(13 \%)$ but not robust to excluding individuals with more than half of classmate parents convicted of crimes (7\%). However, the authors do not provide any supporting tests for their identification assumption neither do they discuss the relevance and validity of their instrument. Instrument validity is key in this work - it seems likely that having children from extremely challenging backgrounds in the classroom would

\footnotetext{
${ }^{8}$ However, Carrell and Hoekstra (2010) show that troubled children have a direct negative spillover effect and significantly decrease the reading and math test scores of their peers.
} 
have an impact on other children in a variety of ways, and not just through a bullying channel. Their negative effects of bullying are even larger when they use teacher reported bullying than with parent reported bullying. It seems likely that these two variables are correlated with the severity of the (unrecorded) actual bullying experienced by the child in different ways. Parents are probably more likely to get to know bullying because of changes in the behavior of their child - for example, making them more reluctant to attend school. In contrast, teachers are more likely to observe minor forms of bullying, as well as major ones.

Ponzo (2013) uses Italian data from the 2017 Trends in International Mathematics and Science Study (TIMMS) and the 2016 Progress in International Reading Literacy Study (PIRLS) programs. They use both OLS estimation and a Propensity Score Matching (PSM) analysis to model the probability of being bullied. Being bullied is defined as having a positive response to any question about experiences of each type of bullying behavior - so this is a very low threshold. In the OLS analysis, the author finds that bullying has bigger adverse effects on numeracy at age 13 than at age seven, while there is a similarly large negative effect of bullying on literacy using the age seven PIRLS data. The author also explores the effects of a count of different forms of bullying as an intensity measure and finds larger negative effects on numeracy.

Oliveira et al (2018) also uses PSM estimation applied to a sample of almost 30,000 children around age 11 in the Brazilian city of Recife in 2013 to measure the effect of bullying on numeracy test performance. Two definitions of bullying are used-'definitely bullied' or 'maybe bullied' - in their descriptive analysis, however the estimates make no distinction between the two definitions. Their results suggest that bullying has a negative impact on test scores of around 0.5 of a standard deviation. Black, younger and students with high BMI are more likely to report being bullied.

Brown and Taylor (2008) use the much earlier National Child Development Study (NCDS) cohort of children born in a particular week in March 1958. It has the advantage that it records long-term outcomes and some, relatively crude, information on the bullies. The strength of this early contribution to the economics literature on bullying is that it uses a high quality and large cohort study that follows children through school and long into the labour market. Being bullied (at 7 and 11) is defined only from a maternal cross-report, and only in quite broad classifications (none, sometimes, often). From these responses the authors construct two indices to measure 
the extent of bulling at ages seven and 11. However, the authors do not account for the downward bias due to measurement error or the (likely, upward) bias due to the possibility of the existence of reverse causality in their estimates. They find that being bullied at school increases the likelihood of failing high school exams by 1.7 percentage points, while a one-point change in their bullying index at age 7 (or 11) decreases earnings by approximately 3.1 (or 2.8) percentage points.

Vignoles and Meschi (2010) use LSYPE (but only up to age 16 outcomes) in their analysis of the effect of bullying educational attainment at 16. They use OLS estimation and rely on lagged, rather than current, bullying (a count of the number of types of bullying reported by the main parent) and control for lagged outcomes, and a rich set of other controls. However, some controls are likely to be "bad" controls (absences, for example). Moreover, the bullying measure is a count of the number of types cross- reported by the parent and so treats violence as equivalent to name-calling. Finally, lagged cross-reported bullying is likely to be a very poor measure of current actual bullying so attenuation due to measurement error is likely to be large.

Sarzosa and Urzua (2015) use a longitudinal survey of 14-18 years olds with matched administrative education data from South Korea, much like our LSYPE data, to identify the determinants of being bullied at age 15 on subsequent mental and physical health, and risky behaviors measured at age of 18 and older. The authors use a wide range of outcomes - depression, smoking, drinking, college attendance, life satisfaction, physical and mental health, and stress. They use a structural model of endogenous bullying and counterfactual outcomes, where latent cognitive and noncognitive skills are used as a source of unobserved heterogeneity. To facilitate identification, they use a feature of the Korean schooling system - random allocation of students to classrooms - as a source of exogenous variation affecting the probability of being victimized. They introduce two additional variables into their system of structural equations - the proportion of peers that self-report as bullies in the class, and the proportion of peers in the classroom that come from a violent family. The bullying definition refers to events where students have been severely teased, threatened, collectively harassed, severely beaten, or robbed. The bullying intensity or the impact of different types of bullying is not been explored in their model; neither do they have access to parental responses in bullying incidence. Sarzosa and Urzua (2015) show that non-cognitive skills reduce significantly the likelihood of being a victim of bullying. 
Table 1: $\quad$ Summary of selected studies in existing literature

\begin{tabular}{|c|c|c|c|c|c|c|}
\hline Authors & $\begin{array}{l}\text { Data } \\
\text { Year }\end{array}$ & Country/Sample & $\begin{array}{l}\text { Estimation } \\
\text { Method }\end{array}$ & $\begin{array}{l}\text { Dependent } \\
\text { Variable }\end{array}$ & Main control variables & Effect size* \\
\hline $\begin{array}{l}\text { Brown and } \\
\text { Taylor } \\
(2008)\end{array}$ & 1958 & $\begin{array}{l}\text { Britain-data } \\
\text { from } 1958 \\
\text { National Child } \\
\text { Development } \\
\text { Study (NCDS) }\end{array}$ & $\begin{array}{l}\text { Ordered } \\
\text { probit; } \\
\text { OLS; IV }\end{array}$ & $\begin{array}{l}\text { Education: } \\
\text { number of GCSEs } \\
\text { at } 16 \text {; degree/none } \\
\text { degree at age } 23 ; \\
\text { wages at age } 23 \text {, } \\
33 \text { and } 42\end{array}$ & $\begin{array}{l}\text { Quadratic in maths and reading test scores, birth weight, body mass } \\
\text { index, controls for number of schools attended, child physical } \\
\text { characteristics, indicator for financial problems/unemployed parent, } \\
\text { whether child is in care or attends special classes, personality, index of } \\
\text { how frequently child prefers to spend time alone, whether child fights, } \\
\text { and is upset by new situations. }\end{array}$ & $\begin{array}{l}6 \% \text { to } 25 \% \text { lower prob } \\
\text { of degree, diploma, O- } \\
\text { level, or no qual; } \\
2.5 \% \text { lower wages }\end{array}$ \\
\hline $\begin{array}{l}\text { Vignoles } \\
\text { and Meschi } \\
(2010)\end{array}$ & $\begin{array}{l}2004- \\
2006\end{array}$ & LSYPE & $\begin{array}{l}\text { Value- } \\
\text { Added } \\
\text { model; } \\
\text { School FE, } \\
\text { RE }\end{array}$ & $\begin{array}{l}\text { KS4 point score; } \\
\text { Attitude to school } \\
\text { at age } 16 ; \\
\text { Bullying at age } 16\end{array}$ & $\begin{array}{l}\text { Gender, ethnicity, if English is the first language, if eligible for free } \\
\text { school meals; if any Special Education Need is identified; number of } \\
\text { unauthorised absences; all attitudinal and behavioural responses that are } \\
\text { likely to influence both parental choice of schooling and pupils' school } \\
\text { engagement. }\end{array}$ & - \\
\hline $\begin{array}{l}\text { Ammermuel } \\
\text { ler (2012) }\end{array}$ & $\begin{array}{l}1965 \\
1969 \\
2003\end{array}$ & $\begin{array}{l}11 \text { EU countries, } \\
\text { data from } 1958 \\
\text { NCDS; } 2003 \\
\text { TIMMS }\end{array}$ & $\begin{array}{l}\text { School } \\
\text { fixed } \\
\text { effects } \\
\text { model }\end{array}$ & $\begin{array}{l}\text { Reading at } 11 / 16, \\
\text { maths/science at } \\
\text { Grade } 4 / 8 \text {; } \\
\text { Highest education } \\
\text { at } 33 \text {; Earnings at } \\
33\end{array}$ & $\begin{array}{l}\text { Gender, parents born abroad, social class of father, parent's interest, free } \\
\text { meal, older/younger siblings, wears glasses, height, attractive look, } \\
\text { twitches, BMI,BSACG score, teacher's initiative to discuss child, pupil- } \\
\text { teacher ratio, school type, dummies for streaming of school, school FE. }\end{array}$ & $\begin{array}{l}\text { Insignificant } 18 \% \text { in } \\
\text { math test scores }\end{array}$ \\
\hline $\begin{array}{l}\text { Ponzo } \\
(2013)\end{array}$ & $\begin{array}{l}2006- \\
2007\end{array}$ & $\begin{array}{l}\text { Italian data from } \\
2006 \text { PIRLS and } \\
2007 \text { TIMSS }\end{array}$ & OLS, PSM & $\begin{array}{l}\text { Reading, maths } \\
\text { and science scores } \\
(\text { Grade } 4 \& 8)\end{array}$ & $\begin{array}{l}\text { Gender, age, native parent, parent's education, total school enrolment, } \\
\text { number of books at home, computer possession, own room, study desk, } \\
\text { economic situation of the family, residence \& city size dummies, \% of } \\
\text { students from disadvantaged families. }\end{array}$ & $\begin{array}{l}\text { Around } 22-23 \% \text { in } \\
\text { reading, maths and } \\
\text { science }\end{array}$ \\
\hline $\begin{array}{l}\text { Eriksen et al. } \\
(2014)\end{array}$ & 2001 & $\begin{array}{l}\text { Denmark- } \\
\text { administrative } \\
\text { data }\end{array}$ & $\begin{array}{l}\text { OLS, IV- } \\
\text { using \% of } \\
\text { troubled } \\
\text { home peers }\end{array}$ & $\begin{array}{l}\text { Grades in Match } \\
\text { and Danish at age } \\
16 \text { (Grade } 9) \text {. }\end{array}$ & $\begin{array}{l}\text { Child controls: gender, birth weight, birth complications, \# younger } \\
\text { siblings, ethnicity, \#moves, mental disorders, emergency ward visit, } \\
\text { psychosocial factors, impaired hearing, wear glasses, cross-eyed; Parent } \\
\text { controls: age at birth, smoking, education, income, managerial level, } \\
\text { mental behaviour, antidepressant. heart medication; classroom FE. }\end{array}$ & $\begin{array}{l}\text { Insignificant IV } 21 \% \\
\text { on GPA grades }\end{array}$ \\
\hline $\begin{array}{l}\text { Oliveira et } \\
\text { al. (2018) }\end{array}$ & 2013 & $\begin{array}{l}\text { Brazil, city of } \\
\text { Recife; 6th grade } \\
\text { students in public } \\
\text { schools }\end{array}$ & OLS, PSM & $\begin{array}{l}\text { Math test } \\
\text { performance } \\
\text { (Grade 6) }\end{array}$ & $\begin{array}{l}\text { Child controls: gender, age, race, BMI, non-cognitive skills, any } \\
\text { reported disease; Parental Controls: family per capita income, higher } \\
\text { education, high school dummies, presence of those responsible for the } \\
\text { student; Teacher Controls: gender, age, experience; School controls: } \\
\text { class size, drop-out levels; absence, and proportion of girls per class; }\end{array}$ & $\begin{array}{l}16 \%-17 \% \text { in math test } \\
\text { score }\end{array}$ \\
\hline $\begin{array}{l}\text { Delprato et } \\
\text { al.(2017) }\end{array}$ & 2013 & $\begin{array}{l}15 \text { Latin } \\
\text { American } \\
\text { countries }\end{array}$ & OLS. PSM & $\begin{array}{l}\text { Maths and } \\
\text { reading test scores }\end{array}$ & $\begin{array}{l}\text { Age, gender, whether repeated a grade, study conditions, family, school } \\
\text { (school type, infrastructure) and teacher characteristic }\end{array}$ & $\begin{array}{l}\text { Around } 10 \% \text { in maths } \\
\text { and } 13 \% \text { in reading }\end{array}$ \\
\hline $\begin{array}{l}\text { Sarzosa and } \\
\text { Urzua } \\
(2015)\end{array}$ & 2003 & $\begin{array}{l}\text { S. Korea KYP- } \\
\text { JHSP longitudinal } \\
\text { survey. }\end{array}$ & $\begin{array}{l}\text { LIML } \\
\text { structural } \\
\text { estimation }\end{array}$ & $\begin{array}{l}\text { Sickness, mental } \\
\text { health, stress, and } \\
\text { smoking at } 18 .\end{array}$ & $\begin{array}{l}\text { Younger siblings, income per capita, both parents present, and father's } \\
\text { education levels. }\end{array}$ & $\begin{array}{l}75 \% \text { increase in } \\
\text { incidence of sickness, } \\
50 \% \text { in mental (ill) } \\
\text { health, stress by } 20 \%\end{array}$ \\
\hline
\end{tabular}


Although bullying here is subjective and self-reported, and therefore likely to be subject to measurement error that might attenuate effects, the authors estimate that victims have significantly higher incidence of self-reported depression, sickness, mental health issues and stress: being bullied at 15 increases sickness and mental health issues by 0.75 and 0.5 of a standard deviation, respectively at 18 . But, unlike our own results, the structural results suggest no effect on life satisfaction, and college enrollment.Another recent study by Delprato et al., (2017) examines the impact of bullying on learning and non-cognitive outcomes for sixth grade students in 15 Latin America countries using 2013 survey data, applying OLS and PSM methods. The study uses an overall measure of bullying and also two types of bullying, i.e. physical and psychological, however no intensity effects are documented. The authors report considerable variation in the prevalence of bullying across countries: physical bullying varies from $11 \%$ in Costa Rica to $26 \%$ in Peru, and psychological bullying between $25 \%$ in Mexico to $40 \%$ in Argentina. For the whole sample of the 15 countries, matching estimates show that bullied students achieve lower scores in mathematics and reading (about 0.11 of a standard deviation in learning outcomes).

Overall, there is little coherence in the existing literature both in the definition of bullying used, and in the interpretation of outcomes. Most studies use one or two definitions and there is little that we can learn about the importance of different types, frequencies, intensities, and repetitiveness of bullying on life outcomes. The problem is confounded by the differences in the dependent variables used, which have mostly focused on educational, rather than on long run outcomes.

\section{Data and Specification}

We use a large representative cohort study of English children, born in 1989/90, who have been followed from age 13/14 to age 25 years, at which point educational attainment has largely been completed and labour market outcomes are recorded. The data is known as Next Steps to the participants, and as the Longitudinal Study of Young 
People in England (LSYPE) to researchers ${ }^{9,10}$ LSYPE covers a wide range of topics, apart from bullying, including family relationships, and attitudes toward school. It includes family, education, and labour market variables, and covers sensitive or challenging issues, such as risky behaviours, and personal relationships. LSYPE selected observations to be representative of the English population, but specific groups were oversampled - in particular, youths from low socioeconomic backgrounds and minorities (see Department of Education, 2010). More details can be found in Centre for Longitudinal Studies (2016) and Anders (2012).

The survey started in 2004 when the young people were at the age of 13/14 (in school year 9). In the first wave of LSYPE, around 15,000 young people were interviewed across more than 700 high schools. The survey continuously followed these individuals for 7 years (age 14-21) and then re-interviewed them in Wave 8 at age 25. The non-response rate in the first wave was approximately $25 \%$, and thereafter there was approximately $10 \%$ attrition in each subsequent annual wave. There was then a four-year break between Waves 7 (age 21) and 8 (age 25) - a period when a lot of new household formation occurs, which contributed to a further drop. There does not seem to have been any substantial attrition as children completed compulsory schooling or when the survey moved to mixed (a choice of either conventional survey home/school visits or new on-line completion) methods. The survey data are matched to an administrative register known as the National Pupil Database (NPD), which includes the LSYPE sample of that 1990 birth cohort and detailed histories of educational attainment.

\subsection{Outcomes}

We study the impact of bullying on the following outcomes-most of which we think of as being long-term ones, but we also include the most important proximate high-stakes educational outcomes:

- Having 5+ GCSE or GNVQ passes, including Maths and English, which is an important criterion for advancing, after 16, along an academic track (" $5+$ GCSE”)

\footnotetext{
${ }^{9}$ The Wave 8 survey sought consent from LSYPE participants to have further administrative data matched to LSYPE. We intend to return to this issue if such a longer-term follow-up of the LSYPE cohort becomes successful.

${ }^{10}$ The data is similar in structure to the earlier, shorter, and smaller, US National Longitudinal Study of Youths (NLSY) dataset that has been extensively used in other longitudinal research studies in other contexts and, in this bullying context, by Lam (2016).
} 
- Having an A-level qualification, or other vocational "Level 3" qualification which attracts UCAS tariff points to contribute to university entrance ("Any A-levels")

- The sum of UCAS tariff points, based on the best three qualifications - these are most commonly A-levels, but can include other qualifications ${ }^{11}$ ("Best 3 A-level points")

- Receiving a university degree ("University degree")

- Natural log of weekly earnings conditional on being an employee ("Income”)

- Unemployment, defined as not being and employee or self-employed, and so includes not in the labour force ("Unemployed")

- The General Health Questionnaire, measuring mental ill-health by a count of conditions from 0 to 12 ("Mental health")

\subsection{Bullying Data}

Our bullying data is unusually comprehensive because it consists of five types, seven frequencies (including none) and three waves of data, providing a large number of possible treatments. The data asks students (and the main parent) whether the child was a victim of bullying in the last 12 months. In particular, in each of the first three Waves of LSYPE (age 14-16), young people were asked whether they had experienced any of five forms of bullying in the last year:

- Upset by name-calling, including text or email (N);

- Excluded from a group of friends (Social exclusion, $\mathrm{S}$ );

- Made to hand over money or possessions (E, for extortion);

- Threatened with violence $(\mathrm{T})$;

- Experienced actual violence. (V)

In addition to type of bullying, the data contains information on frequency: "every day"; "a few times a week"; "once or twice a week"; "once every two weeks"; "once a month"; and "less often than this". ${ }^{12}$

However, estimating close to 100 treatment effects on a dataset with a relatively small sample is unlikely to yield precise estimates. We therefore examine appropriate ways of creating summary measures that seem acceptable to the data and create three different types of bullying treatment variables. In preliminary OLS estimation, available on request, we use nested testing to aggregate types and intensities to achieve a statistically acceptable specification that would be sufficiently parsimonious to allow

\footnotetext{
${ }^{11}$ The best three A-level qualifications are commonly used as the basis of admission by most UK HEIs. See: https://www.ucas.com/sites/default/files/2015-uk-qualifications.pdf.

12 A not insubstantial group indicate the response "it varies" $(\mathrm{n}=885 / 7,569)$, and we set their frequency to missing in the reported results. However, in further analysis that is available on request, we have also explored alternative imputations which do not change the results.
} 
estimation using a number of methods. The first treatment is a binary variable equal to one if a child has experienced any bullying across the three waves, and zero otherwise. The overwhelming majority of the existing quantitative literature uses just one variable to define bullying, and this treatment provides a baseline specification that is comparable with previous studies. Second, we create a richer variable, using factor analysis, which combines information on type and frequency of bullying over the three waves. Finally, we create a multi-valued categorical variable to capture potential heterogeneity in treatment effects. The rationale behind these variables is as follows. We start by imposing cardinal interpretations to the bullying frequency reports. That is, we define frequency not as an indicator for each level, but as a number corresponding to the level. Assuming 200 school days in a year, we make the following imputations:

- "every day" = 200 instances per annum,

- "a few times a week" = 100 instances,

- "once or twice" $=60$ instances,

- "once every two weeks" = 20 instances,

- "once a month" = 10 ,

- "less often than this" $=2$

Rather than impose constraints on the raw data to generate more parsimonious specifications, we first take a data-driven approach using (exploratory) factor analysis. ${ }^{13}$ We conduct the factor analysis on the frequency of bullying variables, which are distinct by type and wave. We find evidence of just one common factor which we interpret as a measure of cumulative bullying intensity. ${ }^{14}$ This score is standardized to have a mean of zero and a standard deviation of one, which allows us to interpret subsequent results in terms of a standard deviation of the bullying intensity. This approach extracts the variation available by type, frequency and wave in a data-driven, pragmatic way. However, it remains restrictive by imposing common effects by bullying type, intensity level and wave.

The third variable we create aims to allow different effects by type and intensity of bullying. We first reduce the number of treatments by collapsing the number of types

\footnotetext{
${ }^{13}$ Factor analysis is commonly used when using data sets with large numbers of observed variables that are thought to reflect a smaller number of underlying latent variables.

${ }^{14}$ These are found using standard procedures according to which only factors with eigenvalues greater than or equal to one should be retained. See Fiorini and Keane (2014) for a similar application. The first factor explains $73 \%$ of the variance. We tried oblique rotation techniques to allow the factors to be correlated but the rotation did not affect the estimates.
} 
to two, by combining the three types that relate to violence (actual violence, threatened violence, and demanding money or belongings under duress) and collapsing the two non-violent types (name calling and social exclusion) into one. This is largely a practical matter to preserve cell sizes. We justify this aggregation considering that some types, e.g., extortion, have a very low participation rate so the data would be unlikely to have the power to detect small effects on outcomes, and the variables in these grouping are naturally correlated: extortion usually occurs because of some implied threat of violence or actual violence.

To reveal heterogeneity in the treatment, by type and intensity, we begin by summing across waves for each of the two types separately, to produce a cumulative sum of bullying instances (this could also be achieved by imposing the same coefficient on each wave's frequency variable for each type separately). This restriction does not allow heterogeneous effects by the timing of bullying, but rather measures the cumulative effect of being bullied. ${ }^{15}$ After collapsing to two types, we create two continuous variables by summing the total instances of violent and non-violent bullying instances across the three waves. For example, because for each type there are a maximum of 200 instances in each wave, the maximum number of non-violent instances across the three waves would be 1200 .

To capture the heterogeneity in the pattern of bullying, we create a multi-valued treatment variable summarising the violent and non-violent frequency variables. We create a variable which takes on nine values indicating each combination of: violent, non-violent, no or little bullying, moderate bullying and high bullying. No or little bullying is defined as a frequency of zero days, or the lowest frequency of two days. This means this lowest category is 0 to 4 days for non-violent bullying ( 2 days multiplied by 2 types) and 0-6 days for violent (maximum of 2 days multiplied by 3 types). High bullying is defined as being in the top quartile of the bullying frequency distribution: experiencing 100 days or more of bullying in a school year. Moderate bullying is the remaining group. Table 2 summarises the nature of this variable.

\footnotetext{
${ }^{15}$ Recent research by Chrystanthou and Vasilakis (2018) explores the determinants of bullying and the role of family support in three waves of the UK Understanding Society panel.
} 
Table 2: $\quad$ Nine categories of the multi-valued treatment

\begin{tabular}{clll} 
& \multicolumn{3}{c}{ Non-violent } \\
\cline { 2 - 4 } None & \multicolumn{1}{c}{ Moderate } & \multicolumn{1}{c}{ High } \\
\cline { 3 - 4 } & $\begin{array}{l}\text { Reference group: } \\
\text { no bullying of } \\
\text { either type (72\%) }\end{array}$ & $\begin{array}{l}\text { No violent bullying; } \\
\text { moderate non- } \\
\text { violent (10\%) }\end{array}$ & $\begin{array}{l}\text { No violent } \\
\text { bullying; high } \\
\text { non-violent (3\%) }\end{array}$ \\
& $\begin{array}{l}\text { Moderate violent } \\
\text { bullying; no non- } \\
\text { violent (3\%) }\end{array}$ & $\begin{array}{l}\text { Moderate violent } \\
\text { bullying; Moderate } \\
\text { non-violent (3\%) }\end{array}$ & $\begin{array}{l}\text { Moderate violent } \\
\text { bullying; high } \\
\text { non-violent (2\%) }\end{array}$ \\
& $\begin{array}{l}\text { High violent } \\
\text { bullying; no non- } \\
\text { violent (1\%) }\end{array}$ & $\begin{array}{l}\text { High violent } \\
\text { bullying; Moderate } \\
\text { non-violent (1\%) }\end{array}$ & $\begin{array}{l}\text { High violent } \\
\text { bullying; high } \\
\text { non-violent (3\%) }\end{array}$
\end{tabular}

Notes: Cell percentages will not add to $100 \%$ due to rounding.

In summary, we have focused on three definitions of bullying - a binary variable indicating whether the pupil has been bullied, of any type or frequency, at any point over the three waves of data (and a corresponding variable based on the parent reports); a continuous variable constructed via a factor analysis of the frequency of each type of bullying in each wave (and a corresponding variable based on the parent reports); and a multi-valued discrete treatment for each combination of violent or nonviolent bullying type, and none, moderate of high cumulative frequency of occurrence over three waves.

\subsection{Summary statistics:}

The most general sample for analysis is restricted to cases who participated in Wave 8, to yield long term outcomes, and also participated in Wave 1 and have complete data on the most basic set of covariates we use $(\mathrm{N}=7,569)$. As we add further covariates and consider outcomes from various sources in our linked administrative data, the sample reduces so we take the approach of including dummy variables that capture missing values wherever possible, to avoid discarding information. Testing for differences in key characteristics across the different estimation samples does not reveal significant differences. ${ }^{16}$

LSYPE contains survey weights, to adjust for the complex survey design (a function of ethnicity, area deprivation and school type, among other factors) and survey

\footnotetext{
${ }^{16}$ Not shown, available by request.
} 
drop-out (modelled as a function of observed characteristics in the data). We may wish to use the weights if we suspect they may be correlated with our treatment effects, i.e. that the survey design or survey drop-out may bias our results. In the main analyses, we do not use the weights, because they are not feasible to incorporate into all of our estimation methods (for instance, IPWRA). However, where we can we have also fitted the models with the survey weights, yielding negligible differences in our parameters estimates, such that we feel confident using the weights would not alter our findings more generally (possibly because we are controlling, or matching on, many of the variables which enter into the survey weights and survey design). ${ }^{17}$ However, we do adjust the standard errors in all analyses for clustering by school, the Primary Sampling Unit of LSYPE.

Summary statistics for the outcomes and the control variables are provided in Table 3. These statistics are unweighted and should not be interpreted as populationrepresentative estimates. Some $45 \%$ of children are male; $69 \%$ self-report white as their ethnicity, $6 \%$ of all children report that English is not their first language; the KS2 and KS3 scores are average points scores from the National Pupil Database (NPD), and are recorded at age 10 and 13 respectively; and $16 \%$ of children live with just one of their biological parents. Parents were asked if their child was in their first ranked secondary school—which we include because a child might be more likely to be bullied and have lower achievement, irrespective of bullying, if the child has not been able to gain admission to her most favoured school. $82 \%$ are placed in their first-choice school. The Index of Deprivation included in the analysis is the IDACI (income deprivation affecting children index), a subset of the Index of Multiple Deprivation, measuring the proportion of children aged 0 to 15 living in income deprived families, defined including people out of work, and people with low income (Department for Communities and Local Government, 2015). Locus of control captures individual beliefs about whether life events are mostly internally or externally determined (Rotter, 1966). People with an external locus of control believe that they cannot have an impact on what happens in life, as events largely depend on circumstances beyond their control. On the other hand, individuals with internal locus of control generally believe that life events are mostly caused by their own decisions and behaviours. We measure

\footnotetext{
${ }^{17}$ Not shown, but available by request.
} 
locus of control using children's responses to six questions (see the Appendix for details) and we use factor analysis to create a continuous index of locus of control. LSYPE includes four questions on working attitudes (see the Appendix for details) and we use factor analysis to create an index of work ethics from these.

The parental education variables reflect the rapid expansion that had occurred in HE provision in the late 80 's and early 90 's so that $37 \%$ of the children have gained a HE degree compared to $25 \%$ for their mothers - the interviewed "main parent" is the parent most involved in the child's schooling, and is almost exclusively the mother. We have a wide variety of outcomes. The proportion attaining 5+ GCSE passes, 69\%, comes from the NPD data and is matched into the LSYPE data. Whether the individual took any A-levels (or equivalent "level 3" qualifications), 51\% in Table 3; and the sum of the points of the best three subjects taken (excluding General Studies - a very broad

Table 3: $\quad$ Summary statistics for key variables

\begin{tabular}{lrrr} 
& Mean & SD & $\mathrm{N}$ \\
\cline { 2 - 4 } Male & 0.45 & 0.50 & 7,569 \\
Child's ethnic group & & & \\
White & 0.69 & 0.46 & 7,569 \\
Asian & 0.17 & 0.38 & 7,569 \\
Black & 0.06 & 0.23 & 7,569 \\
Other ethnic & 0.07 & 0.26 & 7,569 \\
English second language & 0.06 & 0.24 & 7,569 \\
Index of area-deprivation & 0.22 & 0.18 & 7,030 \\
KS2 average points score & 27.43 & 3.92 & 6,945 \\
KS3 average points score & 34.97 & 6.39 & 6,960 \\
Highest parental qualification & & & \\
Degree or HE & 0.25 & 0.44 & 7,569 \\
A-level & 0.14 & 0.34 & 7,569 \\
GCSE & 0.26 & 0.44 & 7,569 \\
Low or no qualifications & 0.30 & 0.46 & 7,569 \\
Age of main parent & 43 & 6.0 & 7,503 \\
Parents separated & 0.16 & 0.36 & 7,569 \\
At first choice school & 0.82 & 0.39 & 7,569 \\
Locus of control & 0.05 & 1.00 & 5,406 \\
Work ethic & 0.13 & 0.96 & 6,204 \\
5+ GCSE & 0.69 & 0.46 & 6,698 \\
Best 3 A-level points & 2289 & 99.40 & 4,018 \\
A-levels & 0.51 & 0.50 & 7,569 \\
University degree & 0.37 & 0.48 & 7,569 \\
Income (weekly) & 303.4 & 72.5 & 7,569 \\
Unemployed & 0.10 & 0.31 & 7,569 \\
Mental health & 2.30 & 3.12 & 7,234 \\
\hline
\end{tabular}


subject that is sometimes taken as a fourth A-level subject) using the grade to points conversion scale prevalent at the time, is taken from wave 7. Earnings are recorded for the individual in wave 8 of LSYPE. Unemployed is defined to include those not in the labour force (i.e. the unemployed are all who are not self-employed or an employee). Mental health is measured using the General Health Questionnaire (GHQ) index, which is a count of up to 12 conditions where a higher score indicates poorer mental health.

Table 4 reports means and standard deviations of key variables by bullying status: whether a child has never been bullied, has been bullied once, or has been bullied multiple times. Boys are slightly more likely to report being bullied than girls. White families are overrepresented among the repeated bullying category compared with other ethnicities. Children in sole parent families are statistically significantly more likely to face multiple instance of bullying compared with those in two-parent families. There appears to be little difference in propensity to be bullied by measures of socio-economic status, such as the area-based deprivation index (IDACI), or parental education level. This makes sense because a key determinant of being bullied is being different from those around you, rather than the levels of any particular variable. There are differences in outcomes by bullying status, especially mental health, unemployment, and income.

Figures 1 and 2 give a sense of the distributions of the frequencies of bullying by type of bullying and wave (among those who report data on both type and frequency of bullying). Figures $1 \mathrm{a}$ and $1 \mathrm{~b}$ shows the extensive margin of victimization experience by type - that is, the proportion of girls and boys reporting (any frequency of) each type of bullying in each Wave. Victimization falls across waves for each type, consistent with the existing literature. Comparing Figures $1 \mathrm{a}$ and $1 \mathrm{~b}$ it is also clear that namecalling and social exclusion are more prevalent for girls and violence more prevalent for boys. Figures $2 \mathrm{a}$ and $2 \mathrm{~b}$ show the intensive margin of victimisation by type and wave - that is, the average numbers of days the young people report experiencing each type of bullying in each wave. Again, victimisation tends to fall over the waves and, conditional on having positive number of instances, boys tend to experience a higher number of instances, especially for violent types. 
Table 4: $\quad$ Differences in key variables by bullying status

\begin{tabular}{|c|c|c|c|c|c|}
\hline & $\begin{array}{l}\text { Never } \\
\text { bullied }\end{array}$ & $\begin{array}{l}\text { Bullied } \\
\text { once }\end{array}$ & $\begin{array}{c}p \\
\text { value }\end{array}$ & $\begin{array}{l}\text { Repeatedly } \\
\text { bullied }\end{array}$ & $\begin{array}{c}p \\
\text { value }\end{array}$ \\
\hline Male & 0.44 & 0.47 & 0.04 & 0.42 & 0.17 \\
\hline White & 0.62 & 0.70 & 0.00 & 0.80 & 0.00 \\
\hline Asian & 0.23 & 0.17 & 0.00 & 0.09 & 0.00 \\
\hline Black & 0.07 & 0.06 & 0.49 & 0.04 & 0.00 \\
\hline Other ethnic & 0.08 & 0.07 & 0.06 & 0.07 & 0.20 \\
\hline ESL & 0.07 & 0.06 & 0.04 & 0.04 & 0.00 \\
\hline Index of deprivation & 0.23 & 0.22 & 0.51 & 0.20 & 0.00 \\
\hline $\mathrm{KS} 2$ average points score & 27.54 & 27.27 & 0.03 & 27.46 & 0.50 \\
\hline $\mathrm{KS} 3$ average points score & 35.23 & 34.62 & 0.00 & 34.95 & 0.18 \\
\hline Parental qual $=$ Degree $/ \mathrm{HE}$ & 0.24 & 0.25 & 0.43 & 0.28 & 0.00 \\
\hline Parental qual = A-level & 0.13 & 0.13 & 1.00 & 0.14 & 0.58 \\
\hline Parental qual $=$ GCSE & 0.25 & 0.26 & 0.49 & 0.28 & 0.03 \\
\hline Parental qual= Low/no qual & 0.33 & 0.31 & 0.30 & 0.26 & 0.00 \\
\hline Age of main parent & 42.54 & 42.42 & 0.46 & 42.44 & 0.56 \\
\hline Parents separated & 0.14 & 0.16 & 0.07 & 0.18 & 0.00 \\
\hline At first choice school & 0.82 & 0.81 & 0.43 & 0.82 & 0.75 \\
\hline Locus of control & 0.12 & 0.02 & 0.00 & -0.01 & 0.00 \\
\hline Work ethic & 0.21 & 0.08 & 0.00 & 0.08 & 0.00 \\
\hline $5+\mathrm{GCSE}$ & 0.74 & 0.67 & 0.00 & 0.65 & 0.00 \\
\hline Best 3 A-level points & 232.31 & 227.57 & 0.22 & 225.04 & 0.06 \\
\hline Any A-levels & 0.53 & 0.48 & 0.00 & 0.53 & 0.92 \\
\hline Has a degree & 0.39 & 0.35 & 0.00 & 0.35 & 0.01 \\
\hline $\ln ($ Income $)$ & 5.67 & 5.67 & 0.62 & 5.72 & 0.00 \\
\hline Unemployed & 0.09 & 0.11 & 0.00 & 0.12 & 0.00 \\
\hline Mental health & 1.74 & 2.44 & 0.00 & 2.92 & 0.00 \\
\hline $\mathrm{N}$ & 3,087 & 2,341 & & 2,141 & \\
\hline
\end{tabular}

Exploration of the degree of serial correlation in bullying across waves suggested that this was high, for all three main types. For this reason, we feel justified in thinking that frequencies for each type could be aggregated across waves - that is, it may not matter than a bullying instance occurred in Wave 1, what matters is that is the cumulative total of bullying experienced. Figure 3 compares the child and parent reports of experiencing bullying. Typically, the child reports show a higher prevalence of bullying. The reports from both child and parents follow a downward trend over the three waves reflecting the decrease in bullying as children mature. In the Appendix, we provide descriptive evidence to get a sense of the outcomes associated with each type and frequency of bullying in Appendix Figure 1. 
Figure 1: $\quad$ Bullying participation by wave and type

(a) Girls

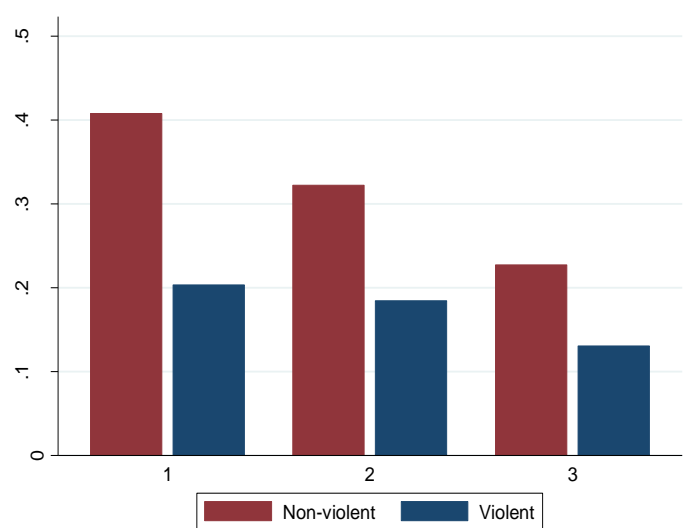

(b) Boys

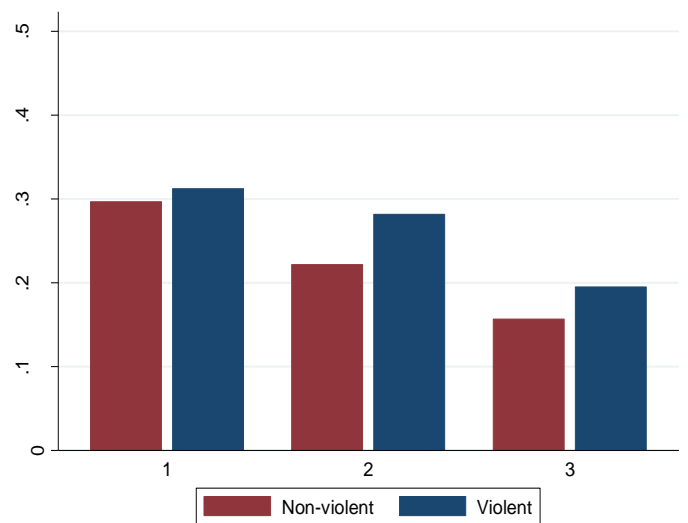

Figure 2:

Bullying days by wave and type

(a) Girls

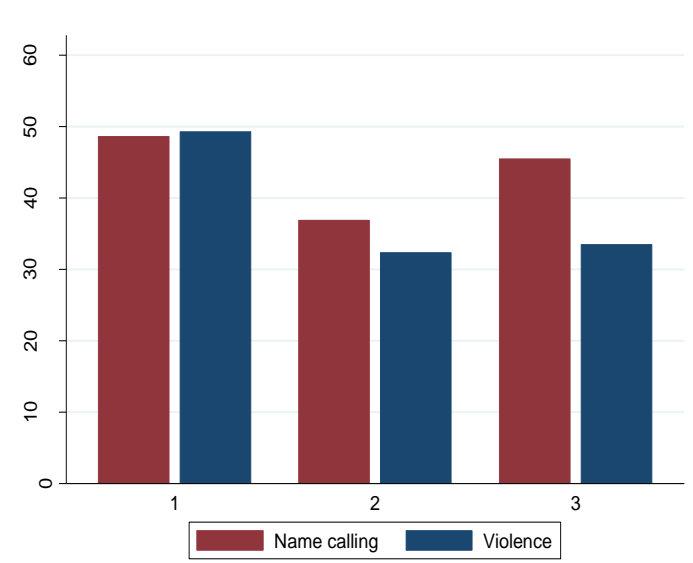

(b) Boys

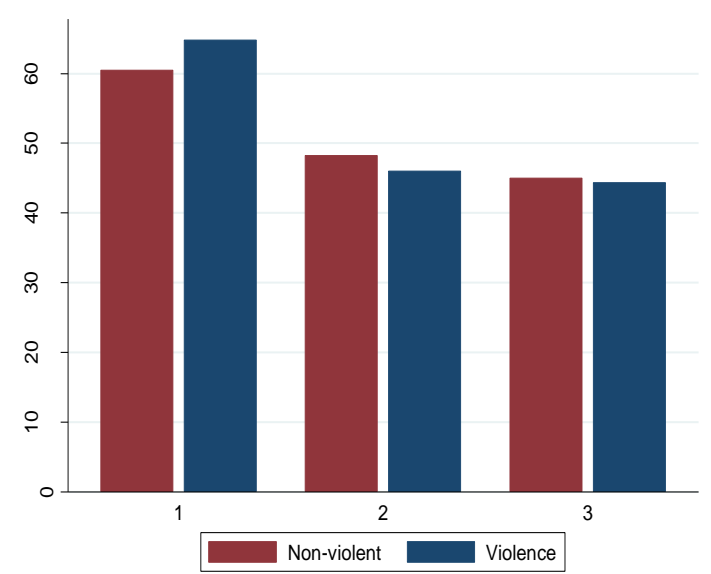

Figure 3: $\quad$ Self and Cross Reported Bullying by wave and gender

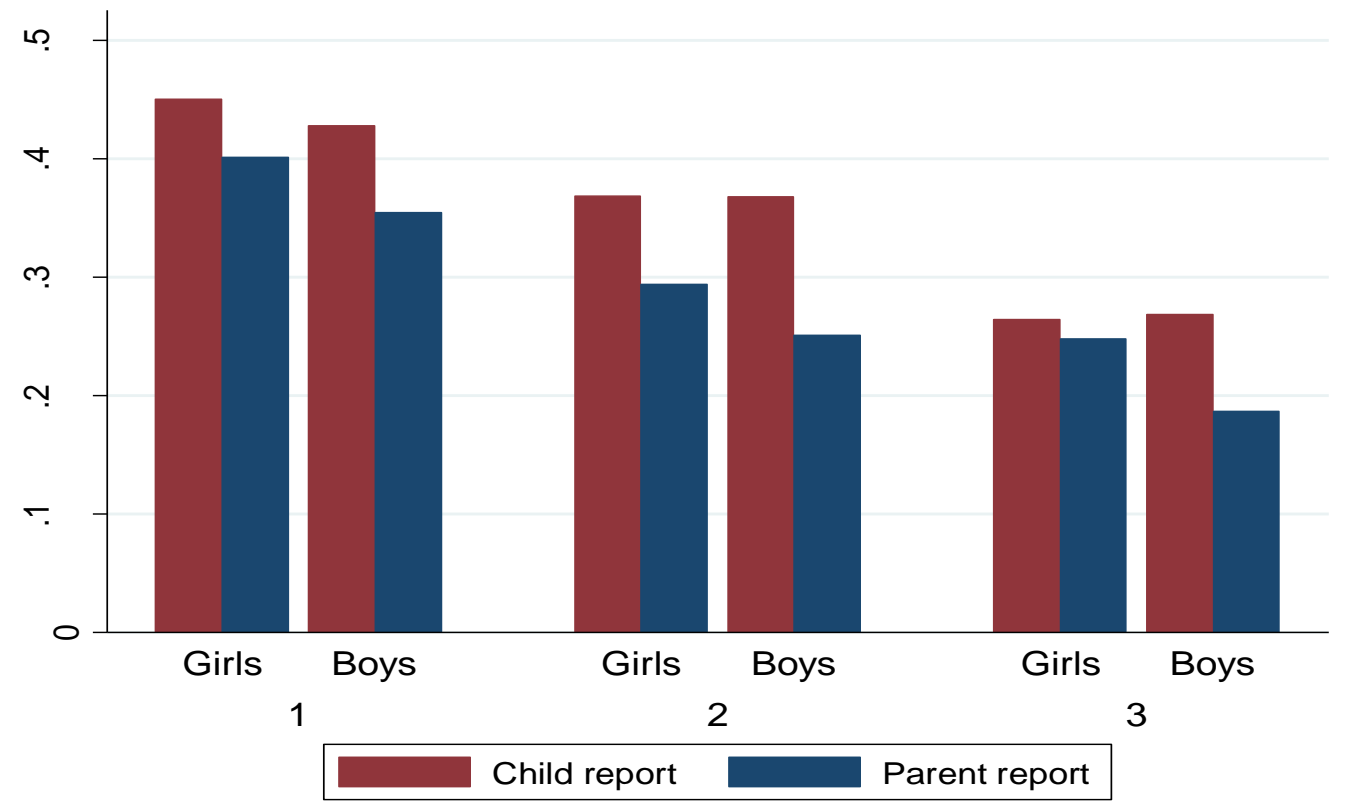

Notes: These charts show the unweighted proportions of cohort members experiencing each type of bullying by survey wave $(1,2,3)$ and gender. 'Non-violent' includes social exclusion and/or name calling, 'Violent' includes threats of violence, actual violence and extortion. 
We group the days of bullying instances into the three levels defined earlier (None, Low, High), and show, for each intensity group cell, the means for each of our outcomes. These figures show the expected pattern, that increasing bullying intensity is associated with worsening outcomes. This pattern is especially pronounced for unemployment and mental ill-health. The graphs also foreshadow non-linearities in the effects of bullying: moving from moderate to high bullying is associated with a larger drop in outcomes, compared with moving from no bullying to moderate bullying. This is an issue we return to in our modelling.

\section{Estimation}

We explore a range of empirical methods, which rely on different identification and estimation assumptions. We first consider OLS estimates, as a benchmark, then propensity score matching (PSM), instrumental variables (IV) and finally treatment effects with inverse-probability-weighted regression (IPWRA).

\subsection{OLS analysis}

We begin by estimating the following simple linear relationship using OLS:

$$
Y_{i h}=\mathbf{B}_{i h}^{\prime} \boldsymbol{\beta}+\mathbf{X}_{i h}^{\prime} \boldsymbol{\gamma}+\epsilon_{h}+\omega_{i h}
$$

where $Y_{\text {ih }}$ represents one of the outcomes, observed at age 16, 18 or 25 years depending on the outcome in question, for individual $i$ who attended high school $h ; \mathbf{B}_{i h}$, represents the bullying treatment variable, for student $i$ attending high school $h ; \mathbf{X}_{i h}$ is a vector of child characteristics (e.g. ethnicity, month of birth, etc), school characteristics (e.g. school type), and family characteristics (e.g. maternal education and marital status), and $\epsilon_{h}$ is a school fixed effect while $\omega_{i h}$ captures unobservables that vary across $i$ and $h$. The inclusion of the school fixed effects allows us to account for unobserved timeinvariant school characteristics, which may affect bullying and students' outcomes at the same time-for example, the disciplinary regime at the school. Using school fixed effects in many of our models captures the idea that it is the relative characteristics of pupils, compared with one's proximate peers, which are important for determining whether a child is bullied.

In this specification the coefficients on our $\mathbf{B}_{i h}$ indicators, $\boldsymbol{\beta}$, are the parameters of interest. While the OLS estimator adjusts for observable factors, the resulting estimates do not necessarily warrant a causal interpretation. The plausibility of the 
conditional independence assumption required for a causal interpretation depends on the relationship between the outcomes and the covariates $\mathbf{X}_{\mathrm{i}}$. As such, it has become common to explore the stability of the parameters of interest by varying the set of control variables $\mathbf{X}_{\mathrm{i}}$. In particular, $\mathbf{X}_{\mathrm{i}}$ might include pre-treatment controls - specifically, KS2 scores that might reflect pre-treatment bullying in primary school. We use three different sets of covariates, each including school fixed effects:

1. A parsimonious specification that includes only those variables that seem plausibly exogenous: gender, ethnicity, month of birth, Government Office Region (GOR) and English being a second language.

2. An intermediate specification which also includes a set of controls which we think of as being predetermined in Wave 1 of the data (age 14): local area deprivation, parental information including age, education, health, income and marital status, low stakes test scores at age 10 (KS2), and whether the school was the parent's first choice school.

3. A general specification that also includes variables that are contemporaneous to the bullying treatment-locus of control, conscientiousness and Key Stage 3 average points score. These variables were measured contemporaneously with bullying and may potentially be bad controls.

We examine the potential role of unobservable variables using recently developed tests that explore the stability of the coefficient(s) of interest in the face of increasing the set of control variables (see Oster, 2017, and Krauth, 2016, which have, in turn, been developed from Altonji et al, 2005). We report the estimates of the parameter $\delta$, developed in Oster (2017), that can be interpreted as the level of selection on unobserved variables, as a proportion of the level of selection on observed variables, required to drive our estimated treatment effect to zero. A higher (absolute) value of $\delta$ indicates that a high level of selection on unobserved variables would be required for our results to be completely explained by omitted variables bias. We use this estimate to guide the selection of an appropriate specification for the subsequent modelling.

We also implement a number of falsification, or placebo, tests. We assess the effects of the binary bullying variable on variables that are either determined before bullying occurred or are measured contemporaneously but should not be affected by bullying. Therefore, we expect to not see any significant effects of bullying in this analysis, unless our observed effects of bullying are driven by confoundedness. As placebo tests, we look at: the effects of bullying on the share of pupils in the school gaining 5+ GCSEs in 2001 (the first wave in the estimation sample is 2004), the 
(current) IDACI index of deprivation of the child's address, the share of White children in the young person's school (in 2004), and the average Key Stage 2 points from the pupil's primary school as measured in 2001.

\subsection{PSM analysis}

We complement least squares estimation with propensity score matching (PSM). Matching offers a number of advantages compared with OLS: increased similarity (balance) in the distribution of covariates between the treated and control group, explicit consideration of the degree of overlap, and a reduced reliance on a linear functional form. The primary approach we use is kernel propensity score matching, with a Gaussian kernel. We complement this with a number of alternative estimation methods, to ensure our results are not an artefact of one particular approach: nearest neighbour (NN) propensity score matching, and multivariate distance matching on the Mahalanobis distance (MDM). For the NN and MDM matching, we also employ a bias adjustment (OLS on the matched sample) to reduce any remaining imbalance in the matched sample. We report a histogram showing the resultant overlap between treated and control units, and a plot summarising the balance statistics.

To evaluate the sensitivity of the estimates to confounding, we employ the sensitivity analysis developed in (Nannicini, 2007; Ichino et. al., 2008) and applied in other applications in labour economics such as Borra, et. al, (2012). This sensitivity analysis simulates the effects of a potential binary confounder on the average treatment effect on the treated. This method is similar in concept to many other sensitivity analyses in the statistics and econometrics literature who also assess the sensitivity to unobserved confounding (for example, Oster 2017). One advantage of this specific approach is that is does not require a parametric outcome model, making it suitable to use in a matching context

The idea is that we may suspect that the conditional independence assumption may not hold, given the covariates we observe. However, we suggest that conditional on an omitted variable, denoted $U$, the assumption would now plausibly hold. Matching on $U$ in addition to the vector $\mathbf{X}$ would allow us to obtain a consistent estimate of the ATET. By specifying the joint distribution of $U$, the binary treatment (denoted $B$ ) and outcome (denoted $Y$ ), we can compute the "unbiased" ATT, which accounts for the confounding effects of $U$. We can compare this to our original, potentially "biased" 
estimate, which doesn't adjust for $U$, to assess the difference made by accounting for the unobserved covariate.

To operationalise the method, one needs to specify the distribution of a hypothesised $U$, in relation to $B$ and $Y$. Equation 2 highlights the maintained simplifying assumption that $U$ is binary and independent of $\mathbf{X}$. After specifying $p_{i j}$, the relevant value of $U$ is assigned to each observation, depending on which category of $i, j$ they are in, and $U$ is included in the calculation of the ATET as an additional covariate. For a given set of parameters, the matching procedure is performed multiple times with varying draws of $U$, and the estimate of the ATET is the average over the estimate of the ATET in each simulation. The standard errors are calculated using Rubin's rules for computing standard errors across multiple datasets.

$$
p_{i j} \equiv \operatorname{pr}(U=1 \mid B=i, Y=j)=\operatorname{pr}(U=1 \mid B=i, Y=j, \mathbf{X})
$$

The first way we operationalise this is to pick $U$ such that the unbiased effect would be zero, and then assess the substantive plausibility of such a confounder. A second way to operationalise this is to specify $U$ to mimic the distribution of some observed confounder, which may represent a more plausible scenario. Therefore, in addition to a hypothetical $U$ which drives the treatment effect to zero, we also look at the potential confounding effects of hypothesised confounders which have the same distribution as some variable that is observable. We choose three such variables to explore this: the "sole parent family" variable; the "English second language" variable; and a binary variable (which we call "outlier") that indicates being in either the top or bottom decile of the Key Stage 2 distribution in their school (i.e., compared with being in the middle of the distribution as the base category). We choose these particular variables as it seems plausible that they may possibly affect both the probability of being bullied and the outcomes.

To assess the economic plausibility of each confounder $U$, we report both the selection effect and the outcome effect (Nannicini, 2007; Ichino et. al., 2008). ${ }^{18}$ The selection effect quantifies the degree to which the posited unobserved covariate increases selection into being bullied: specifically, the change in the odds of being bullied associated the binary confounder taking the value one compared with zero. The outcome effect quantifies the degree to which the posited unobserved covariate

\footnotetext{
${ }^{18}$ See the Appendix for a specific definition of these quantities.
} 
increases the average outcome: specifically, the change in the odds of a binary outcome associated with having the confounder taking the value one compared with zero. The idea is that if an unobservable must have implausibly large selection and outcome effects to materially change our results then this would provide evidence supporting the robustness of our results.

The OLS and PSM analysis so far has employed a simple binary treatment. To improve on this simple treatment, we also consider a continuous treatment constructed using factor analysis on the frequency of each type of bullying in each wave. Beyond this data reduction approach we consider multiple treatments defined by the varying intensities and types of bullying.

\subsection{Instrumental Variable analysis}

To account for measurement error as a plausibly important source of endogeneity in the model, and for the possibility that the coefficients of interest could be attenuated because of this, we use an instrumental variable approach using parental cross-report of bullying as an instrument for self-reported bullying. Our identification strategy is based on cross-reported bullying types and overall frequency. The estimation model consists of a first stage model of bullying (defined as binary or continuous variable), as a function of maternal cross reported bullying, defined in the same way as the dependent variable. The exclusion restriction rests on the assumption that bullying reported by the main parent does not affect individual's long-term outcomes directly. IV estimation uses a smaller sample, because they rely on the frequency report of both parents and children to be non-missing, in all waves, not just at the extensive margin. The estimated model has the following two-stages:

$$
\begin{aligned}
& B_{i h}=\mathbf{M P B}_{i h} \theta^{\prime}+\mathbf{X}_{i h}^{\prime} \gamma_{1}+\vartheta_{h}+\varepsilon_{i h} \\
& \mathrm{Y}_{i h}=\widehat{\boldsymbol{B}}_{i h} \beta^{\prime}+\mathbf{X}_{i h}^{\prime} \gamma_{2}+\epsilon_{h}+\omega_{i h}
\end{aligned}
$$

where $\mathbf{M P B}_{i h}$ is the cross-report by the main parent of child $i$ in school $h$.

One possible concern in this analysis is that parents who report bullying may be systematically different from those who do not report it, and that they may put some strategies in place in order to support their child and help her/him navigate through these difficult experiences. If these characteristics or strategies also affect long-term outcomes, our estimates could be biased. A similar argument has been used in other 
educational production function examples. This kind of parental behaviour is more likely to be found among parents who are more involved in their children's lives and possibly more able to support their children. We expect these parental characteristics to have a positive effect on children's long-term outcomes, and therefore this is likely to make our OLS estimates more conservative. That is, we identify lower bounds.

\subsection{Treatment effects with IPWRA analysis}

We also examine the role of different types of bullying using inverse probability weighted regression adjustment (IPWRA) treatment effects estimation based on Imbens and Wooldridge (2009) and its implementation in Cattaneo et al. (2010). ${ }^{19}$ We use IPWRA to explore the effects of a multi-valued treatment taking nine values: each combination of no bullying, low bullying and high bullying frequency, for two types of bullying (violent and non-violent).

Specifically, the probability of "treatment" (in this context, having a certain combination of violent/non violent and low/high frequency bullying) is estimated using a multinomial logit specification. The inverse of these predicted probabilities are used as weights in a second-stage regression (Wooldridge, 2007; Wooldridge, 2010; and Imbens and Wooldridge, 2009). IPWRA re-weights the sample based on the inverse probability of treatment, and fits OLS regression on the reweighted sample. The IPWRA estimator has the so-called "double robustness property" (Wooldridge, 2007 and 2010) in that only one of the two equations in the model must be correctly specified to consistently estimate the parameters of interest. That is, estimates in the second stage (the outcome equations) are robust to misspecification of the first stage (the multinomial logit model of treatment propensities) provided that the second stage is correctly specified. Similarly, estimates from the first stage are robust to the second step provided the weighting is correctly specified. Nonetheless, estimation by IPWRA relies on the conditional-independence assumption in order to identify the effect of bullying on long term outcomes. If we had enough information on the observable differences between youths with and without the treatments, we can heavily weight treated observations that have similar observables to untreated individuals and obtain unbiased estimates of the causal relationship between bullying and long term

\footnotetext{
${ }^{19}$ These estimates are calculated using the teffects iwpra routine in Stata (Stata Corp, 20I7).
} 
outcomes (Mendolia and Walker, 2015). Technically, this approach increases the similarity of the distribution of covariates in the treated and control groups via the reweighting, leading to reduced reliance on functional form of the OLS specification.

\section{Results}

Table 5 shows the OLS results for the "Any bullying" measure, which is typically what the existing literature has measured. In the body of the text we report results only for boys and girls pooled (with a gender control included). ${ }^{20}$ The most straightforward specification of the treatment, that is common in the literature is the single treatment model defined as "Any bullying". OLS results are reported in Table 5 for short term effects on having 5+ GCSE passes at age 16, taking A-levels at age 18, and A-level score used as one factor determining university admission; intermediate outcomes associated with university (having a degree by age 25) and long run outcomes at age 25 (log income, being unemployed, and the GHQ score).

Specification 1 includes as covariates the child's gender, ethnicity, month of birth, Government Office Region (GOR) and English being a second language, along with the school fixed effects. Adjusting for these basic controls, we observe large detrimental effects of experiencing bullying. The probability of gaining 5+ GCSE passes at age 16 is reduced by 6.3 percentage points (10\% reduction from a mean of 0.69). The probability of staying on in school to take a A-levels or an equivalent is reduced by 4.6 percentage points ( $9.0 \%$ reduction from a mean of .51 ), and the UCAS points gained from those qualifications are reduced by about 5 points ( $5 \%$ of a standard deviation). Turning to longer run outcomes, income at age 25 years is reduced by $2.3 \%$ (7 GBP per week reduction from a mean income of 303.4 in the sample). The probability of being unemployed increases by 3.5 percentage points (35\% from a mean of 0.10). Perhaps most strikingly, the GHQ mental ill-health index increases by 0.97 , a large effect size of about one third of a standard deviation.

Evidently, being bullied is strongly associated with deleterious outcomes, making comparison within schools, and controlling for a basic set of covariates. However, these effects may be driven, to some extent, by confounding. Specification 2 aims to address this by adding a rich set of relevant controls, associated with both being

\footnotetext{
${ }^{20}$ In the Appendix we present results for boys and girls separately - as a general rule we find that girls are more sensitive to bullying, however measured, than boys for virtually all outcomes.
} 
bullied and child outcomes. Specification 2 adds: local area deprivation (IDACI), parental information, including parental age, education, health status (long term condition), income and sole parent status, average points score from Key Stage 2 (KS2), and whether the school was the parent's first choice school.

For the GCSE outcome, A-level participation, income at age 25 years, and university degree, this addition of relevant controls reduces the effects size by about half, and the effects remain statistically significant (aside from having a university degree). For example, the probability of gaining 5+ GCSE passes at age 16 is now $4 \%$ (reduced by 2.4 percentage points); the probability of staying on in school to take A-levels or equivalent is around $-2.5 \%$ (reduced by 2 percentage points); the probability of having a university degree is reduced by 1 percentage point (not significant); and the effect on income at age 25 years is to reduce this by $1.0 \%$ ( $£ 3$ per week reduction from a mean income of 303.4 in the sample). Other outcomes remain with a similar effect size: A-level points gained from those qualifications is reduced by about 6 points $(6 \%$ of a SD), and again the GHQ mental ill-health index increases by 0.91 , a robust large effect size of $29 \%$ of a standard deviation.

Looking at the estimates of the $\delta$ parameter, these typically increase in absolute value, moving from Specification 1 to Specification 2, indicating that the level of selection on unobserved variables required to drive our treatment effects to zero is now higher in Specification 2. It is natural then to consider adding further controls to improve the credibility of the findings, which motivates Specification 3, which adds personality traits and further academic tests scores variables. Specifically, locus of control, work ethic, and Key Stage 3 average points score. However, these variables are measured contemporaneously with the bullying treatment, therefore it is not clear whether they are best suited as controls or mediators. Assessing the change in the $\delta$ estimate, this figure typically decreases moving from Specification 2 to Specification 3 , potentially suggesting that we have worsened the selection problem by controlling for these variables. Thus, we select Specification 2 as our preferred specification for the remaining analyses, and we explore the credibility of this in more detail with further sensitivity checks, beginning with a falsification exercise. A negative estimate of delta can be generated if the observables are positively correlated with the treatment, and the unobservables are negatively correlated with the treatment (Oster, 2017). 


\begin{tabular}{|c|c|c|c|c|c|c|c|}
\hline $\begin{array}{l}\text { Dependent } \\
\text { variable }\end{array}$ & $5+\mathrm{GCSE}$ & Any A-levels & $\begin{array}{l}\text { Best } 3 \text { A-level } \\
\text { points }\end{array}$ & $\operatorname{Ln}$ (income) & $\begin{array}{l}\text { University } \\
\text { degree }\end{array}$ & Unemployed & Mental health \\
\hline \multicolumn{8}{|c|}{ Specification 1} \\
\hline$\beta$ & $-0.0633 * * *$ & $-0.0457 * * *$ & -4.927 & $-0.0225 * * *$ & $-0.0227 *$ & $0.0348 * * *$ & $0.969 * * *$ \\
\hline se & $(0.0118)$ & $(0.0112)$ & $(3.412)$ & $(0.00429)$ & $(0.0118)$ & $(0.00726)$ & $(0.0751)$ \\
\hline $\mathrm{N}$ & 6,698 & 7,569 & 4,018 & 7,569 & 7,569 & 7,569 & 7,234 \\
\hline$\delta$ & 0.48 & -0.18 & 4.16 & -0.49 & 0.05 & 0.86 & 2.00 \\
\hline \multicolumn{8}{|c|}{ Specification 2} \\
\hline$\beta$ & $-0.0349 * * *$ & $-0.0249 * *$ & $-5.880 *$ & $-0.00955^{* * *}$ & -0.0109 & $0.0281 * * *$ & $0.911 * * *$ \\
\hline se & $(0.00968)$ & $(0.0121)$ & $(3.509)$ & $(0.00344)$ & $(0.0126)$ & $(0.00744)$ & $(0.0816)$ \\
\hline $\mathrm{N}$ & 6,133 & 6,413 & 3,671 & 6,413 & 6,413 & 6,413 & 6,162 \\
\hline$\delta$ & 0.67 & 0.20 & 29.6 & -15.7 & 0.06 & 0.18 & 0.37 \\
\hline \multicolumn{8}{|c|}{ Specification 3} \\
\hline$\beta$ & -0.0141 & 0.00408 & -4.237 & -0.00390 & 0.00236 & $0.0159 *$ & $0.894 * * *$ \\
\hline se & $(0.0112)$ & $(0.0148)$ & (3.904) & $(0.00428)$ & $(0.0148)$ & $(0.00906)$ & $(0.0977)$ \\
\hline $\mathrm{N}$ & 4,269 & 4,436 & 2,649 & 4,436 & 4,436 & 4,436 & 4,282 \\
\hline$\delta$ & 0.35 & -0.042 & 0.27 & -2.18 & -0.016 & 0.102 & 0.332 \\
\hline
\end{tabular}

Notes: Robust standard errors, clustered by school, in parentheses. $* * * \mathrm{p}<0.01, * * \mathrm{p}<0.05, * \mathrm{p}<0$. School fixed effects are included in all specifications. $\beta=$ coefficient on bullying treatment; $\operatorname{se}(\beta)$ robust standard error of $\beta ; \delta=$ estimate of delta parameter implemented in — psacalc- and developed in Oster (2017), which indicates how much selection on unobserved variables would be required to drive the beta estimate to zero, measured as proportional to the selection on observed variables. 


\begin{tabular}{|c|c|c|c|c|c|c|c|}
\hline $\begin{array}{l}\text { Dependent } \\
\text { Variable: }\end{array}$ & 5+ GCSE & Any A-levels & $\begin{array}{l}\text { Best } 3 \text { A-level } \\
\text { points }\end{array}$ & Ln(income) & $\begin{array}{l}\text { University } \\
\text { degree }\end{array}$ & Unemployed & Mental health \\
\hline \multicolumn{8}{|c|}{ Specification 1} \\
\hline$\beta$ & $-0.321 * * *$ & $-0.200 * * *$ & $-27.65 * * *$ & $-0.120 * * *$ & $-0.168 * * *$ & $0.101 * * *$ & $1.735 * * *$ \\
\hline (se) & $(0.0388)$ & $(0.0377)$ & $(10.45)$ & $(0.0151)$ & $(0.0347)$ & $(0.0224)$ & $(0.248)$ \\
\hline $\mathrm{N}$ & 6,698 & 7,569 & 4,018 & 7,569 & 7,569 & 7,569 & 7,234 \\
\hline \multicolumn{8}{|c|}{ Specification 2} \\
\hline$\beta$ & $-0.0920 * * *$ & -0.0463 & $-17.69 *$ & $-0.0374 * * *$ & $-0.0864 * *$ & $0.0566^{* *}$ & $1.768 * * *$ \\
\hline (se) & $(0.0313)$ & $(0.0375)$ & (10.29) & $(0.0117)$ & $(0.0387)$ & $(0.0244)$ & $(0.278)$ \\
\hline $\mathrm{N}$ & 6,133 & 6,413 & 3,671 & 6,413 & 6,413 & 6,413 & 6,162 \\
\hline \multicolumn{8}{|c|}{ Specification 3} \\
\hline$\beta$ & $-0.0982 * * *$ & -0.0103 & -16.78 & -0.0213 & -0.0616 & $0.0727 * *$ & $1.889 * * *$ \\
\hline (se) & $(0.0336)$ & $(0.0437)$ & (11.55) & $(0.0136)$ & $(0.0452)$ & $(0.0296)$ & $(0.318)$ \\
\hline $\mathrm{N}$ & 4,269 & 4,436 & 2,649 & 4,436 & 4,436 & 4,436 & 4,282 \\
\hline
\end{tabular}

Notes: Robust standard errors, clustered by school, in parentheses. *** $\mathrm{p}<0.01,{ }^{* *} \mathrm{p}<0.05,{ }^{*} \mathrm{p}<0.1 \mathrm{GMM}$ results were almost identical. 
In Table 6 we report the results of IV estimation, with a binary treatment and binary instrument. We use parental reporting of any bullying as an instrument for childreported bullying. We are instrumenting to handle measurement error arising from misreporting in the discrete subjective self-reports, and as expected, the effect size tend to be larger after using IV compared with the corresponding OLS results. In general, IV results confirm our OLS findings and show a substantial negative impact of bullying on all considered outcomes. The lower $\delta$ estimates in Specification 3 of Table 5, relative to Specification 2, suggest that we have added bad controls, worsening the selection problem.

Table 7 presents results from an important falsification test. We show OLS estimates of the effects of being bullied on various outcomes, which we feel should not be greatly affected by our bullying treatment: the share of white pupils in the school, the pupil's deprivation index, and historical information on school performance. Observing an effect on these outcomes would suggest we are conflating the bullying effects on long run outcomes with general omitted variable bias. Conditioning on the variables listed in Specification 2, we do not observe any significant effects on these outcomes, providing support for the veracity of our results and with the credibility of Specification 2 in controlling for the key determinants of bullying and outcomes.

Table $7 \quad$ OLS linear estimates of the effect of "any bullying" (a binary treatment variable). on predetermined variables (falsification tests)

$\begin{array}{lllll}\text { Outcomes: } & \begin{array}{l}\text { Share of White } \\ \text { pupils at school } \\ (2004)\end{array} & \begin{array}{l}\text { IDACI index of } \\ \text { deprivation } \\ \text { (wave 2) }\end{array} & \begin{array}{l}\% \text { of pupils 5+ } \\ \text { GCSEs in 2001 }\end{array} & \begin{array}{l}\text { Average KS 2 } \\ \text { points in 2001 }\end{array}\end{array}$

\begin{tabular}{lllll}
$\beta$ & $\begin{array}{lll}0.0902 \\
(0.473)\end{array}$ & $\begin{array}{l}0.00548 \\
(0.00366)\end{array}$ & $\begin{array}{l}-0.179 \\
(0.459)\end{array}$ & $\begin{array}{l}0.989 \\
(1.140)\end{array}$ \\
$\mathrm{N}$ & 6,413 & 6,260 & 5,702 \\
& & & \\
\hline
\end{tabular}


Aside from the issues associated with identification, our estimates could also be driven by the functional form imposed in the OLS estimation. Therefore, we also investigate propensity score matching. In Table 8 , the propensity score findings show strikingly similar pattern to those in Specification 1. This suggests that the Table 6 results are not driven by the functional form of the OLS model.

Table 9 reports on a sensitivity analysis to deviations from the conditional independence assumption in the propensity score matching (Nannicini, 2007; Ichino et., al, 2008). We first consider the plausibility of a binary confounder that would drive our treatment effects to zero. Taking the first outcome in Table 9 as an example gaining 5+ GCSE passes, we see there would need to be large outcome and selection effects to make this effect completely disappear. The binary confounder $U$ would need to increase the odds of being bullied by a factor of at least 4.5 and decrease the odds of gaining 5+ GCSE passes by a factor of 0.2. While this may be plausible, looking across the outcomes, the longer run effects are most robust (would require the most extreme confounder). For instance, for mental health, the binary confounder $U$ would need to increase the odds of being bullied by a factor of at least 9 and decrease the odds of being in the top quartile of the GHQ distribution by a factor of 31 . This type of extreme confounder seems an unlikely scenario.

Table 8: $\quad$ Propensity score estimates of the effects of "Any bullying" (a binary treatment variable)

\begin{tabular}{lccccc} 
& ATT & $\begin{array}{c}\text { Std. } \\
\text { error }\end{array}$ & $\begin{array}{c}\mathrm{N} \\
\text { (control) }\end{array}$ & $\begin{array}{c}\mathrm{N} \\
\text { (treated) }\end{array}$ & Total N \\
\hline 5+ GCSE & $-0.0710^{* * *}$ & 0.0102 & 2,401 & 3,732 & 6,133 \\
Any A-levels? & $-0.0526 * * *$ & 0.0112 & 2,526 & 3,887 & 6,413 \\
Best 3 A-level points & $-7.4607 * *$ & 2.7570 & 1,549 & 2,122 & 3,671 \\
ln(Income) & $-0.0169 * * *$ & 0.0046 & 2,526 & 3,887 & 6,413 \\
Has a degree & $-0.0219 * *$ & 0.0121 & 2,526 & 3,887 & 6,413 \\
Unemployed & $0.0354 * * *$ & 0.0076 & 2,526 & 3,887 & 6,413 \\
Mental health & $0.9597 * * *$ & 0.0800 & 2,417 & 3,745 & 6,162
\end{tabular}

Notes: Kernel matching estimates implemented using attk in Stata; ATT $=$ average treatment effect on the treated; se, standard error (bootstrapped with 100 replications). *** $\mathrm{p}<0.01, * * \mathrm{p}<0.05, * \mathrm{p}<0.1$. The covariates included in the propensity score model are from Specification 2. 
To assess more realistic potential confounders, we assess the effects of simulated variables that mimic the distribution of relevant observed variables in our data, in relation to the treatment and outcome. The next three panels assess the effects of using each of our selected variables to be potential confounders in our data: being in a sole parent family, having English as a second language, and being in the top decile or bottom decile of the Key Stage 2 distribution on the child's school. These variables were chosen as variables that may reflect perceived or actual differences from one's classmates, which would shape both the propensity of being bullied and have direct effect on the outcome. While we adjust for school fixed effect in much our analyses, such that the data are in terms of deviations from the school averages, there may be further unobserved confounders based on "being different" which are not captured.

Beginning with effects of the simulated unobserved confounder mimicking the distribution of the sole parent family variable, this would reduce the effect on the GCSE variable by about 3\% i.e. (comparing row 1 with the equivalent row in column 1 of Table $9,-0.071$ to 0.069$)$, the A-level variable by $4 \%$, and the income effect by about $6 \%$, but has negligible effects on the other treatment effects. Looking at the selection and outcome effects, these appear to more substantively plausible compared with the simulated confounder devised to fully eliminate the effects. The simulated unobserved confounder mimicking the distribution of English as a Second Language has little impact on the treatment effects, aside from reducing the effect on mental health by about $1 \%$. Finally, we examine the simulated unobserved confounder mimicking the distribution of being in the tails of the prior ability distribution. This would reduce the effect on the GCSE variable by about $2 \%$ and has negligible effects on the other treatment effects.

Our conclusion from this analysis is that, overall, scenarios emulating realistic levels of confounding could reduce our treatment effects by between 0\%-6\%, depending on which outcomes is considered. Therefore, it seems unlikely that our results could be entirely driven by selection. The type of confounder required for this to happen appears to be substantively implausible. That being said, the effects on longer run outcomes - mental health and unemployment - are the most robust, compared with the short run academic outcomes. 
Table 10 looks at the effects of the continuous treatment (bullying factor), using OLS and Table 11 shows IV results, instrumenting with a parental cross-report. The unit of treatment is a one-standard deviation increase in the continuous bullying factor created using factor analysis. The pattern of findings is consistent with the binary treatment results, after now incorporating richer information from both the extensive and intensive margin of bullying. The IV results, while less precise, tend to be larger after instrumenting to handle measurement error, as we already noticed in the previous tables and as expected. In Web Appendix Table 4 and 5, we report the OLS and IV results separately by boys and girls, typically finding larger effects among girls although the difference in effects is not statistically significant, and we do not comment further on gender differences.

Finally, we explore the role of type and frequency together using treatment effects and IPWRA. The aim is, in contrast to the existing literature, to show the merit of viewing bullying as a multi-valued treatment problem. Figure 4 summarises the treatment effects for the four long run outcomes: (a) university degree, (b) income, (c) unemployed, (d) mental health. The dots are our point estimates, while the lines represent the $95 \%$ confidence intervals. The figures for the remaining short-term outcomes are presented in Figure 5.

Even with this minimal extension that considers just two types of bullying at three levels of intensity (none, low, high), we find systematic effects of both type and frequency using IPWRA. Especially for the longer run outcomes, it appears that much of the effects is driven through the most intense forms of bullying - high intensity, violent bullying. Other types and frequencies also have effects, especially for mental health where any combination of NV and V bullying, whether at high or low intensity, statistically significant adverse effects - raising the mental ill-health count by between 0.5 and 1.5 where the mean is 2.3 . The effects on income are large and negative (-4\%) only for the relatively small proportion of the population who experience high intensity $\mathrm{V}$ bullying and either high or low NV bullying. The results in Figure 5 suggest that these income effects may stem from negative impacts of bullying combinations on the probability of attaining 5+ GCSEs or any A level. These results strongly reject the idea that a single treatment is sufficient to capture the complex effects of bullying. 
Table 9: $\quad$ Sensitivity analysis for propensity Score estimates of the effects of "Any bullying” (a binary treatment variable).

\begin{tabular}{|c|c|c|c|c|c|c|}
\hline Outcomes: & $\begin{array}{l}5+ \\
\text { GCSEs }\end{array}$ & $\begin{array}{c}\text { Any A- } \\
\text { levels }\end{array}$ & $\begin{array}{c}\text { Best } 3 \\
\text { A-level } \\
\text { points }\end{array}$ & $\operatorname{Ln}($ Income $)$ & Unemployed & $\begin{array}{l}\text { Mental } \\
\text { health }\end{array}$ \\
\hline ATT assuming unconfoundedness & -0.071 & -0.053 & -7.470 & -0.017 & 0.035 & 0.96 \\
\hline With $U$ chosen to make ATT $\approx 0$ & 0.004 & 0.001 & -0.014 & -0.008 & -0.007 & 0.004 \\
\hline Selection effect & 4.460 & 2.942 & 3.541 & 1.714 & 3.109 & 9.015 \\
\hline Outcome effect & 0.211 & 0.314 & 0.335 & 0.089 & 12.857 & 31.177 \\
\hline ATT, $U$ mimicking "Sole parent family" & -0.069 & -0.051 & -7.433 & -0.016 & 0.035 & 0.957 \\
\hline Selection effect & 1.239 & 1.195 & 1.171 & 1.329 & 1.245 & 1.248 \\
\hline Outcome effect & 0.610 & 0.617 & 0.768 & 0.318 & 1.441 & 1.110 \\
\hline ATT, $U$ mimicking “English second language" & -0.070 & -0.053 & -7.383 & -0.018 & 0.036 & 0.953 \\
\hline Selection effect & 0.640 & 0.577 & 0.611 & 0.689 & 0.607 & 0.638 \\
\hline Outcome effect & 0.970 & 0.893 & 1.119 & 0.037 & 1.817 & 0.694 \\
\hline ATT, $U$ mimicking “Outlier in school Key Stage 2 dist'n" & -0.070 & -0.053 & -7.493 & -0.017 & 0.035 & 0.959 \\
\hline Selection effect & 1.095 & 1.109 & 1.043 & 1.149 & 1.117 & 1.139 \\
\hline Outcome effect & 0.864 & 1.129 & 1.695 & 1.108 & 0.784 & 1.039 \\
\hline$N$ & 6,133 & 6,413 & 3,671 & 6,413 & 6,413 & 6,162 \\
\hline
\end{tabular}

Notes: Kernel matching estimates, ATT = average treatment effect on the treated. 
Table 10: $\quad$ OLS estimates of the effects of 'bullying factor'

\begin{tabular}{llllllll}
$\begin{array}{l}\text { Dependent } \\
\text { Variable: }\end{array}$ & 5+ GCSE & Any A-levels & $\begin{array}{c}\text { Best 3 A- } \\
\text { level points }\end{array}$ & Ln(income) & $\begin{array}{c}\text { University } \\
\text { degree }\end{array}$ & Unemployed & $\begin{array}{c}\text { Mental } \\
\text { health }\end{array}$ \\
\hline Specification 1 & & & & & & & \\
B & $-0.0489 * *$ & $-0.0461 * * *$ & -1.780 & $-0.0182 * * *$ & $-0.0276^{* * *}$ & $0.0197 * * *$ & $0.296 * * *$ \\
se & $(0.00825)$ & $(0.00748)$ & $(2.930)$ & $(0.00332)$ & $(0.00635)$ & $(0.00596)$ & $(0.0488)$ \\
N & 4,861 & 4,890 & 3,053 & 4,890 & 4,890 & 4,890 & 4,704
\end{tabular}

\section{Specification 2}

$\begin{array}{llllllll}\beta & -0.0140^{* *} & -0.0228 * * * & -1.203 & -0.00678^{* *} & -0.0115^{*} & 0.0111 * & 0.297 * * * \\ \mathrm{Se} & (0.00661) & (0.00834) & (2.947) & (0.00267) & (0.00688) & (0.00581) & (0.0530) \\ \mathrm{N} & 4,450 & 4,464 & 2,780 & 4,464 & 4,464 & 4,464 & 4,307\end{array}$

Notes: Robust standard errors, clustered by school, in parentheses. $* * * \mathrm{p}<0.01,{ }^{* *} \mathrm{p}<0.05,{ }^{*} \mathrm{p}<0 . \beta=$ coefficient on bullying treatment; $\operatorname{se}(\beta)$ robust standard error of $\beta$. 
Table 11: $\quad$ IV estimates of the effects of 'bullying factor'

\begin{tabular}{llllllll}
$\begin{array}{l}\text { Dependent } \\
\text { Variable: }\end{array}$ & 5+ GCSE & Any A-levels & $\begin{array}{l}\text { Best 3 A- } \\
\text { level points }\end{array}$ & Ln(income) & $\begin{array}{l}\text { University } \\
\text { degree }\end{array}$ & Unemployed & $\begin{array}{l}\text { Mental } \\
\text { health }\end{array}$ \\
\hline & & & & & & & \\
Specification 1 & & & & & & & \\
$\beta$ & $-0.102^{* * *}$ & $-0.0946^{* * *}$ & -21.84 & $-0.0521^{* * *}$ & $-0.0835^{* * *}$ & $0.0429^{* *}$ & $0.735^{* * *}$ \\
se & $(0.0268)$ & $(0.0235)$ & $(15.02)$ & $(0.0121)$ & $(0.0209)$ & $(0.0180)$ & $(0.217)$ \\
N & 3,758 & 3,780 & 2,424 & 3,780 & 3,780 & 3,780 & 3,643 \\
& & & & & & & \\
Specification 2 & & & & & & & $0.775^{* * *}$ \\
$\beta$ & -0.0287 & $-0.0497^{*}$ & -20.20 & $-0.0243^{* * *}$ & $-0.0561^{* * *}$ & 0.0287 & $(0.250)$ \\
se & $(0.0196)$ & $(0.0255)$ & $(14.63)$ & $(0.00893)$ & $(0.0212)$ & $(0.0192)$ & 3,337 \\
N & 3,444 & 3,455 & 2,209 & 3,455 & 3,455 & 3,455 & \\
\hline
\end{tabular}


(a) University degree

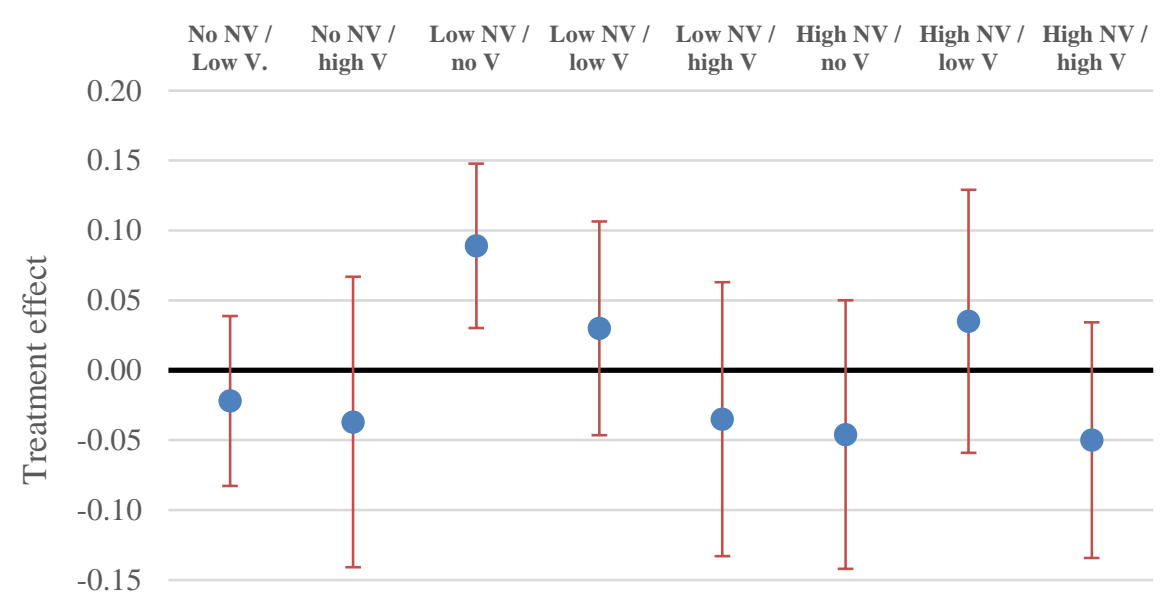

$-0.20$

(b) Income

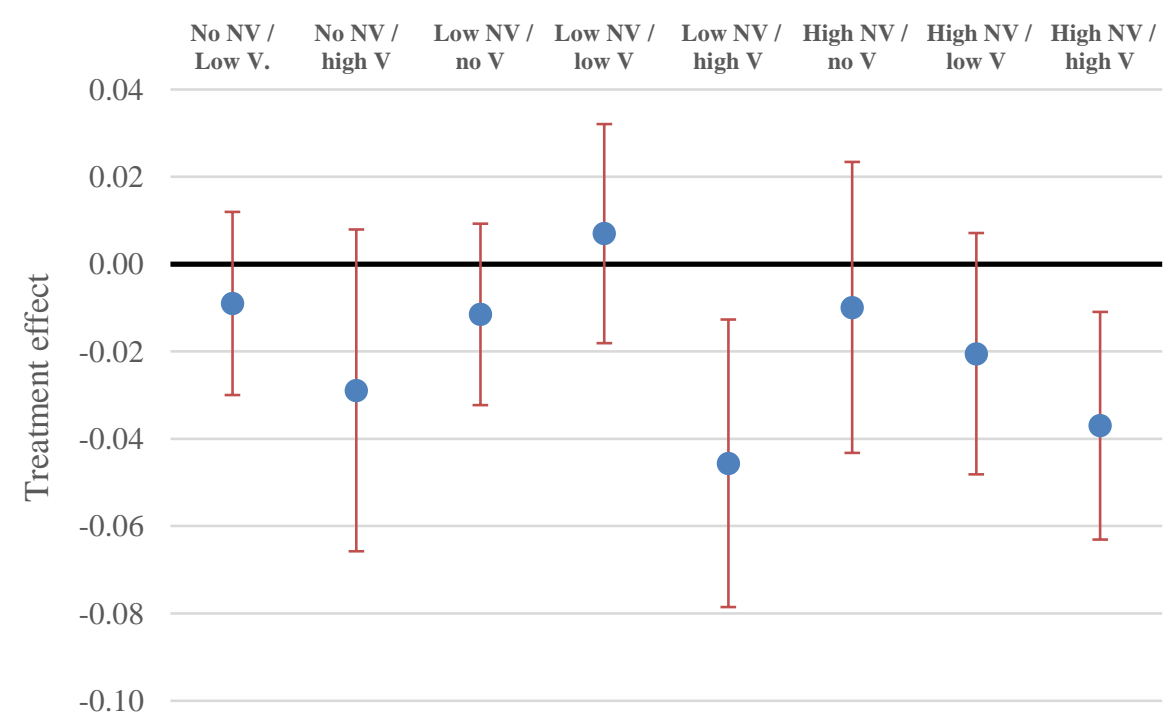

(c) Unemployed

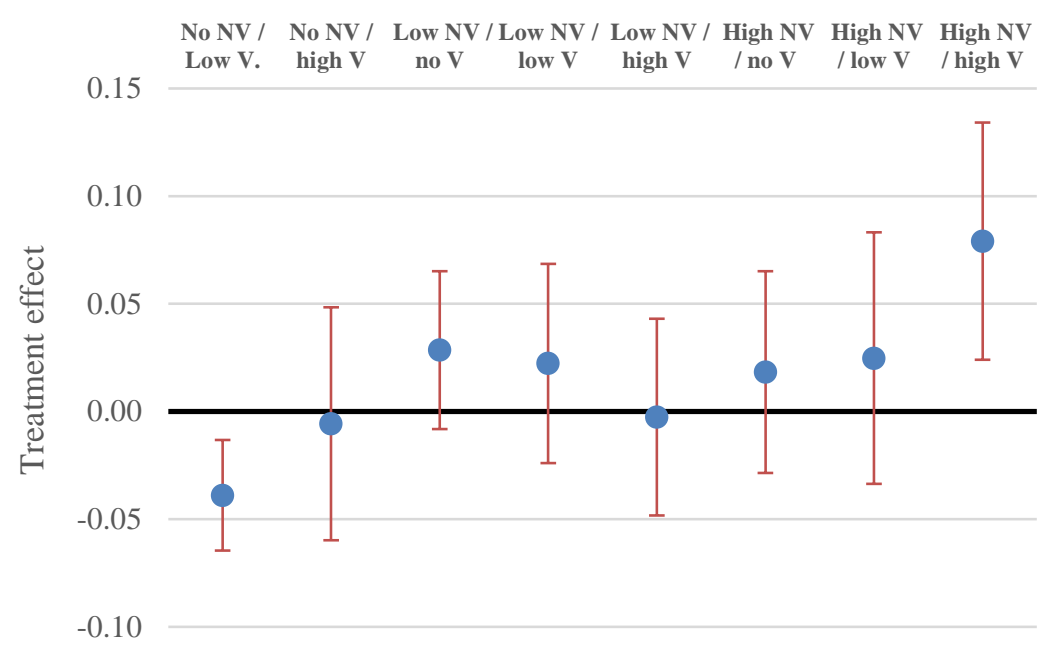

(d) Mental health

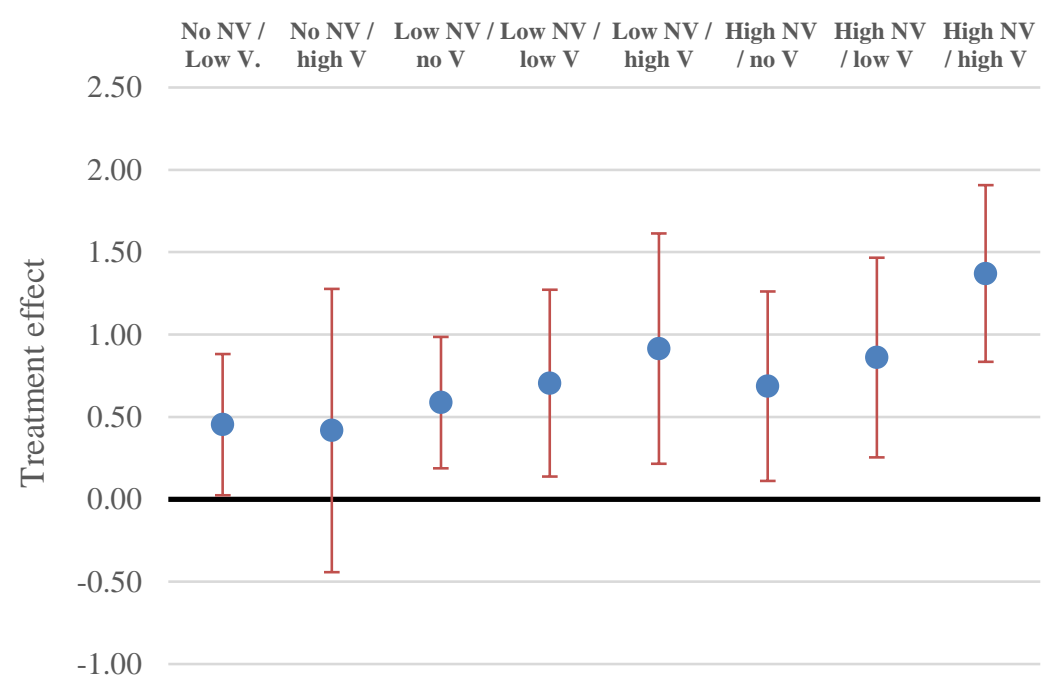


Figure 5 Estimated short term effects from IPWRA model

(a) $5+G C S E$

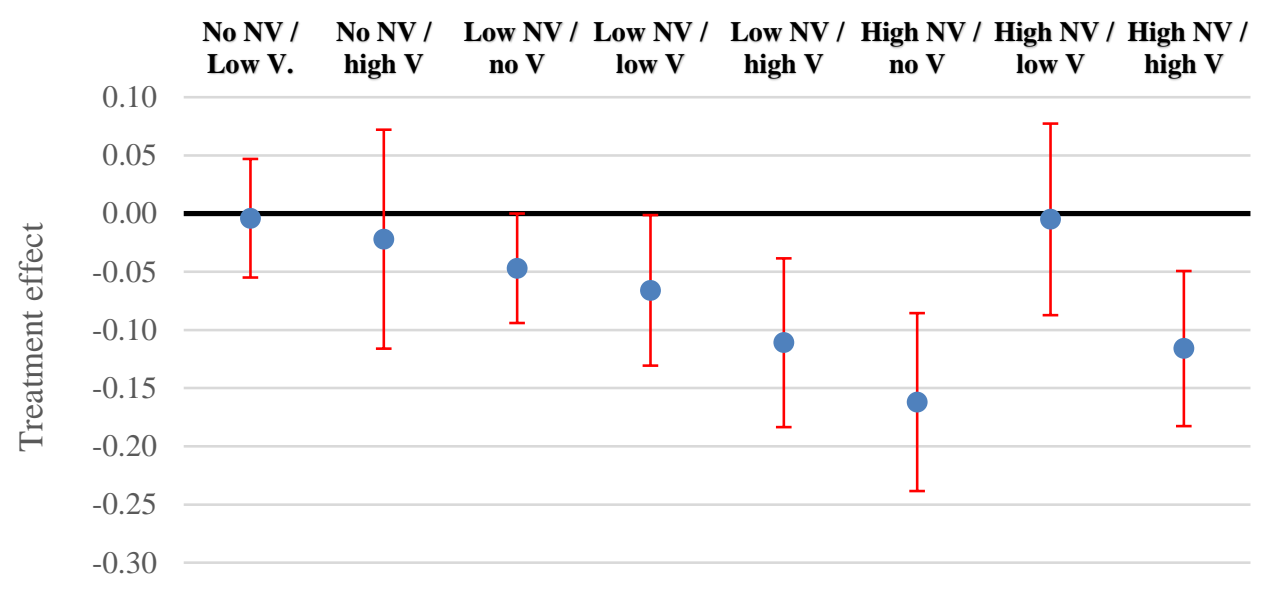

(b) Any A-levels

No NV / No NV / Low NV Low NV / Low NV High NV High NV High NV

Low $\mathrm{V}$. high $\mathrm{V}$ / no $\mathrm{V}$ low $\mathrm{V} /$ high $\mathrm{V} /$ no $\mathrm{V}$ / low $\mathrm{V} /$ high $\mathrm{V}$

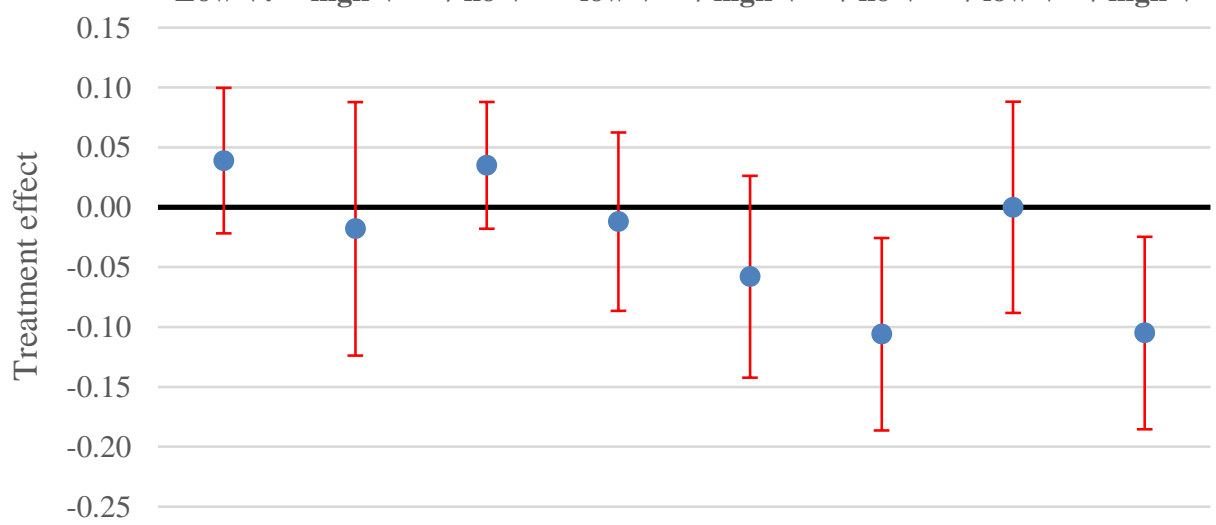

(c) Best 3 A-level points

No NV / No NV / Low NV Low NV / Low NV High NV High NV High NV Low $\mathrm{V}$. high $\mathrm{V}$ / no $\mathrm{V}$ low $\mathrm{V} /$ high $\mathrm{V} /$ no $\mathrm{V} /$ low $\mathrm{V} /$ high $\mathrm{V}$

60.00

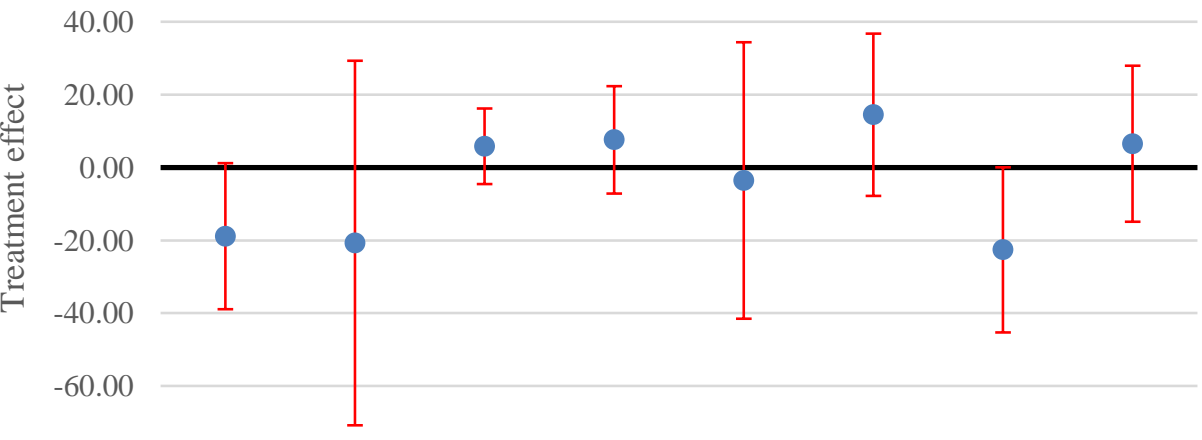

$-80.00$ 


\section{Conclusion}

This paper investigates the effects of bullying in secondary school on later academic and labour market outcomes. We do this by exploiting a rich conditioning set of observables, using a range of estimation methods: OLS, matching, weighting and instrumental variables. The data come from a large high quality cohort study in England, the LSYPE, confidentially linked with administrative data on education records. Our empirical findings show that school bullying has negative consequences for short run academic outcomes and persists to have adverse long-term effects-the strongest effects are on mental health, and we also find effects on unemployment and income measured at 25 years.

We conduct a comprehensive battery of sensitivity tests to explore our main identifying and estimation assumptions. The results of this indicate that it is very unlikely, indeed implausible, that our effects are entirely driven by selection on unobserved variables. A more credible interpretation of these results is that our effect sizes could potentially be reduced, but not eliminated, by unobserved selection, in some cases by up to $6 \%$. Even in this scenario, the estimate effects remain large enough to be of substantive importance. The most robust effects are mental ill-health and unemployment. Being bullied exerts long run deleterious effects of children's life outcomes. Based on our analyses, we feel confident that this finding is not an artefact of a particular estimation or identification assumption.

The results have relevance for policy. Although schools have flexibility in how they deal with bullying, all schools are expected to have a policy. In practice, schools tend to take a zero-tolerance approach to bullying. Our results suggest that low levels of non-violent bullying have modest effects, but higher intensity bullying has much larger effects. We also tentatively suggest that violent bullying has a greater effect than non-violent bullying. These findings suggest that the long run consequences of bullying should not be underestimated, and perhaps more policy should be targeted more heavily on the extreme cases of violent and intense cases. 


\section{REFERENCES}

Altonji, J.G., T.E. Elder and C.R. Taber (2005), "Selection on Observed and Unobserved Variables", Journal of Political Economy, 113, 51-184.

Ammermueller, A. (2012), "Violence in European schools: A widespread phenomenon that matters for educational production", Labour Economics, 19(6), 908-922.

Anders, J. (2012), "Using the Longitudinal Study of Young People in England for research into Higher Education access," DoQSS Working Papers 12-13, Department of Quantitative Social Science, Institute of Education, University College London.

Arseneault, L., Bowes, L., and S. Shakoor, S. (2010). "Bullying victimization in youths and mental health problems: 'Much ado about nothing'? Psychological Medicine, 40, 717-729

Ashenfelter, O. and C. Rouse (1998), "Income, Schooling, and Ability: Evidence from a New Sample of Identical Twins", Quarterly Journal of Economics, 113, 253-284.

Bingley, P. and A. Martinello (2017), "Measurement Error in Income and Schooling and the Bias of Linear Estimators", Journal of Labor Economics, 35,1117-1148.

Brown, S., and Taylor, K. (2008) Bullying, education and earnings: Evidence from National Child Development Study, Economics of Education Review, 27, 387-401.

Bond, L., Carlin, J., Thomson, L. Rubin, K., and Patton, G. (2001), "Does bullying cause emotional problems? A prospective study of Young teenagers", BMJ, 323, 480484.

Borra, C., Iacovou, M., \& Sevilla, A. (2012), The effect of breastfeeding on children's cognitive and noncognitive development. Labour Economics, 19, 496-515.

Burgess, S., Graves, E., Vignoles, A., and D. Wilson (2015), "What Parents Want: School Preference and School Choice”, Economic Journal, 124, 1262-1289

Carrell, S., and M. Hoekstra (2010), 'Externalities in the Classroom: How Children Exposed to Domestic Violence Affect Everyone's Kids', American Economic Journal: Applied Economics, 2(1): 211-228.

Cattaneo, M. (2010), "Efficient semiparametric estimation of multi-valued treatment effects under ignorability", Journal of Econometrics, 155, 138-154.

Centre for Longitudinal Studies. (2018). Next Steps: Sweeps 1-8, 2004-2016, 14th Edition, Study Number: 5545, UK Data Service.

Chrystanthou and Vasilakis (2018), "The Dynamics and Determinants of Bullying Victimisation", IZA DP 11092.

Delprato, M., Akyeampong, K. and M. Dunne (2017), 'The impact of bullying on students' learning in Latin America: A matching approach for 15 countries', International Journal of Educational Development, 52: 37-57.

Department of Education (2010), "A review of the Longitudinal Study of Young People in England (LSYPE): recommendations for a second cohort", Research Report DFERR048.

Department of Education (2017), "Preventing and Tackling Bullying, Advice for Headteachers, Staff and Government Bodies", HMSO London. 
Department for Communities and Local Government (2015) The English Index of Multiple Deprivation (IMD) 2015-Guidance)

Due, P., B.E. Holstein, J. Lynch, F. Diderichsen, S. N. Gabhain, P. Scheidt, C. Currie and the Health Behaviour in School-Aged Children Bullying Working Group (2005), "Bullying and symptoms among school-aged children: international comparative cross sectional study in 28 countries", European Journal of Public Health, 15, 128-132.

Eriksen, T., Nielsen, H., and Simonsen, M. (2014), "Bullying in Elementary School”, Journal of Human Resources, 49 (4), 839-871.

Farrington, D., and M. Ttofi, (2009) School-based programs to reduce bullying and victimization, Campbell Systematic Review, 2009.

Fiorini, M., and Keane, P. (2014), "How the allocation of children's time affects cognitive and non-cognitive development?", Journal of Labour Economics, 32(4), 787-836.

Ford, R., T. King, N. Priest, and A. Kavanagh (2017), "Bullying and mental health and suicidal behaviour among 14-to 15-year-olds in a representative sample of Australian children”, Australian and New Zealand Journal of Psychiatry, 51 (9), 897-908.

Harmon, C. (2017), "How Effective is Compulsory Schooling as a Policy Instrument?", IZA World of Labor, 348

Harmon, C. and I.Walker (2000), "The Return to the Quantity and Quality of Education: Evidence for Men in England and Wales", Economica, 67, 19-35

Ichino, A., Mealli, F., \& Nannicini, T. (2008). From temporary help jobs to permanent employment: What can we learn from matching estimators and their sensitivity?. Journal of applied econometrics, 23(3), 305-327.

Imbens, G., and Wooldridge, J. (2009), "Recent Developments in the Econometrics of Program evaluation" Journal of Economic Literature, 47(1), 5-86.

Klomek A., A. Sourander, and M. Gould (2010) "The association of suicide and bullying in childhood to young adulthood: A review of cross-sectional and longitudinal research findings", The Canadian Journal of Psychiatry, 55, 282-288.

Krauth, B. (2016), "Bounding a linear causal model using relative correlation restrictions", Journal of Econometric Methods, 5, 117-141.

Ladd, G., I. Ettekal, B., Kochenderfel-Ladd (2017), "Peer Victimization trajectories from kindergarten through high school: Different pathways for children's school engagement and achievement?" Journal of Educational Psychology, 109 (6), 826-841.

Lam, J. (2016), "Bullying and human capital accumulation: Evidence from the National Longitudinal Survey of Youth, 1997" (2016), CUNY Academic Works, http://academicworks.cuny.edu/hc_sas_etds/38.

Light, A. and Flores-Lagunes, A. (2006), "Measurement Error in Schooling: Evidence from Samples of Siblings and Identical Twins", BE Journal of Economic Analysis \& Policy.

Mendolia, S., and Walker, I. (2015), "Youth unemployment and personality traits", IZA Journal of Labour Economics, 4(19), 1-26.

Murphy, R., Scott-Clayton, J. and G. Wyness (2017), "The End of Free College in England: Implications for Quality, Enrolments and Equity". NBER Working Paper 
23888.

Nannicini, T. (2007), "Simulation-Based Sensitivity Analysis for Matching Estimators," Stata Journal, 7, 334-350.

OECD (2017): "How Much of a Problem Is Bullying at School?" PISA in Focus No. 74, OECD Publishing, Paris.

Oliveira, F.P., T. Almeida de Menezes and G. Irffi (2018), "Bullying effect on student's performance", Economia, 19, 57-73.

Olweus, D. (1993), Bullying in school: What we know and what we can do. Oxford: Blackwell.

Olweus, D. (2013), "School bullying: Developments and some important challenges", Annual Review of Clinical Psychology, 9, 751-780.

Oster, E. (2017), "Unobservable Selection and Coefficient Stability: Theory and Evidence", Journal of Business \& Economic Statistics, DOI: 10.1080/07350015.2016.1227711.

Ponzo M. (2013), "Does bullying reduce educational achievement? An evaluation using matching estimators", Journal of Policy Modelling. 1057-78.

Sarzosa, M. and Urzia, S. (2015), "Bullying among adolescents: the role of cognitive and non-cognitive skills", NBER Working Paper 21631.

Sharp, S. (1995), "How much does bullying hurt? The effects of bullying on the personal wellbeing and educational progress of secondary aged students", Educational and Child Psychology, 12(2), 81-88.

Smith, P.K. and F. Thompson (2014), "What works best to help stop bullying in schools?", The Conversation, August 7.

Thompson, F. and P. Smith (2010), "The Use of Effectiveness of Anti-Bullying Strategies in Schools", Research Report DFE-RR098.

Ttofi, M. and D. Farrington (2011), "Effectiveness of school-based programs to reduce bullying: a systematic and meta analytic review", Journal of Experimental Criminology, 7, 27-56.

University College London, UCL Institute of Education, Centre for Longitudinal Studies. (2018). Next Steps: Sweeps 1-8, 2004-2016: Secure Access. [data collection]. 4th Edition. UK Data Service. SN: 7104, http://doi.org/10.5255/UKDA-SN-7104-4

Vignoles, A. and Meschi, E. (2010), “The determinants of non-cognitive and cognitive school outcomes" Report to the Department of Children, Schools and Families, CEE Special Report 004.

Woods, S. and Wolke, D. (2004) "Direct and relational bullying among primary school children and academic achievement”, Journal of School Psychology, 42, 135-155. 


\section{APPENDIX}

\section{Questions in $L S Y P E$}

\section{Locus of control}

I can pretty much decide what happens in my life

If someone is not a success in life, it is usually his fault

How well you get in this world is mostly a matter of luck

Even if I do well at school, I will have a hard time

People like me do not have much of a chance

If you work hard at something, you will usually succeed

Possible answers: Strongly agree, Agree, Disagree, Strongly disagree

\section{Work ethic}

Doing well at school means a lot to me

At school, I work as hard as I can

Working hard at school now will help me to get on later in life

If you work hard at something, you will usually succeed

Possible answers: Strongly agree, Agree, Disagree, Strongly disagree 
Appendix Figure A1 Outcome means by type of bullying and level of bullying.

a) 5+ GCSEs - Non-violent and violent
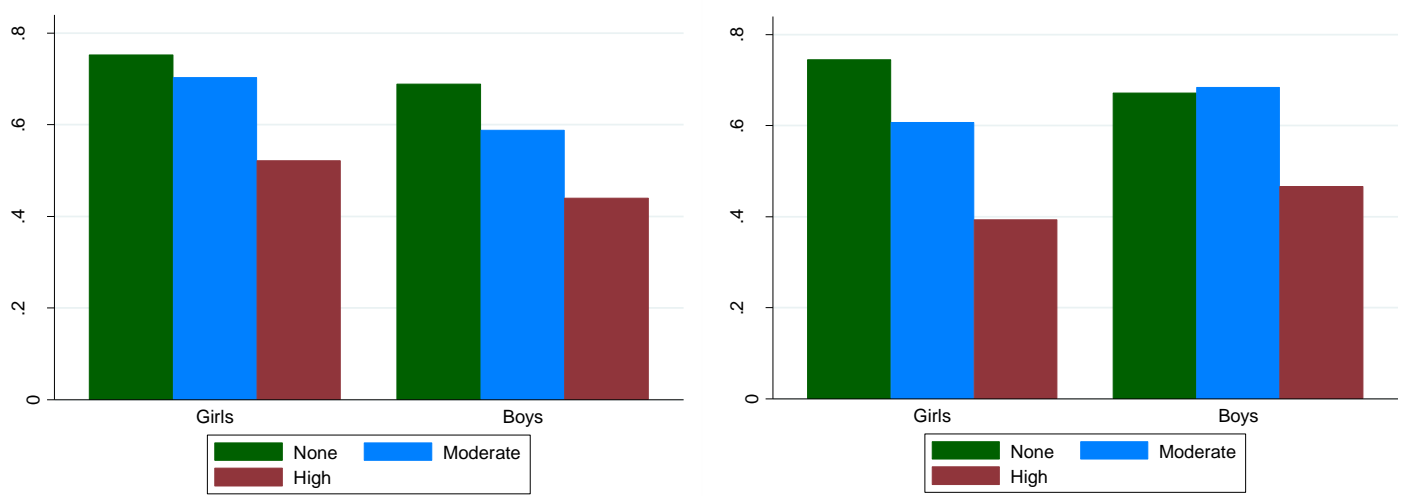

b) Any A-levels - Non-violent and violent
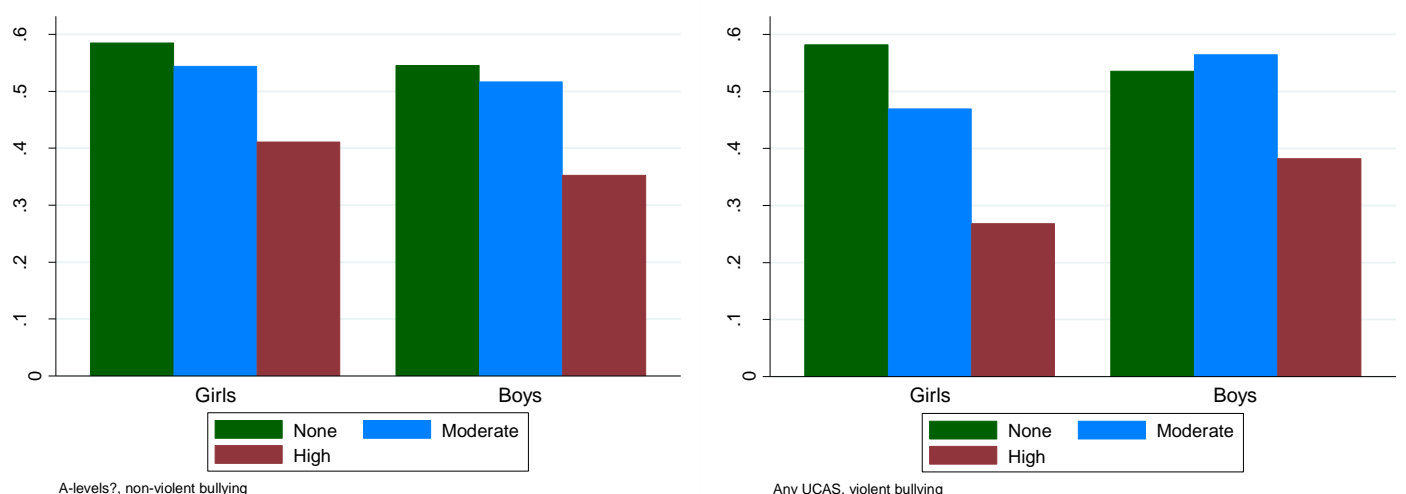

c) Best 3 A-level points- Non-violent and violent
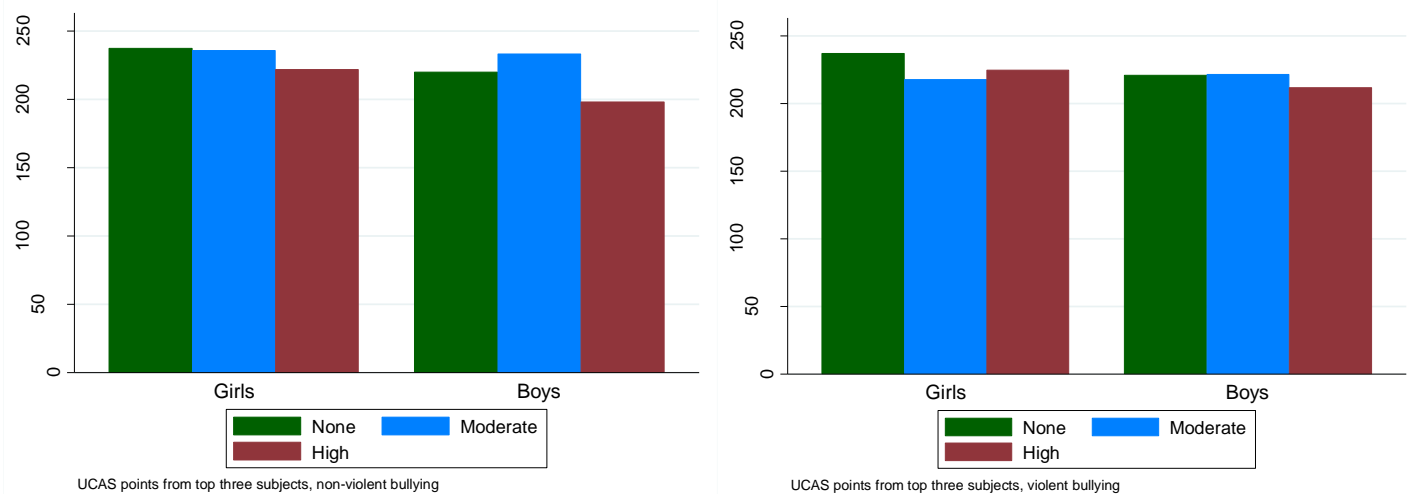
Appendix Figure A2 contd. Outcomes by type of bullying and level of bullying.

d) Unemployed - Non-violent and violent
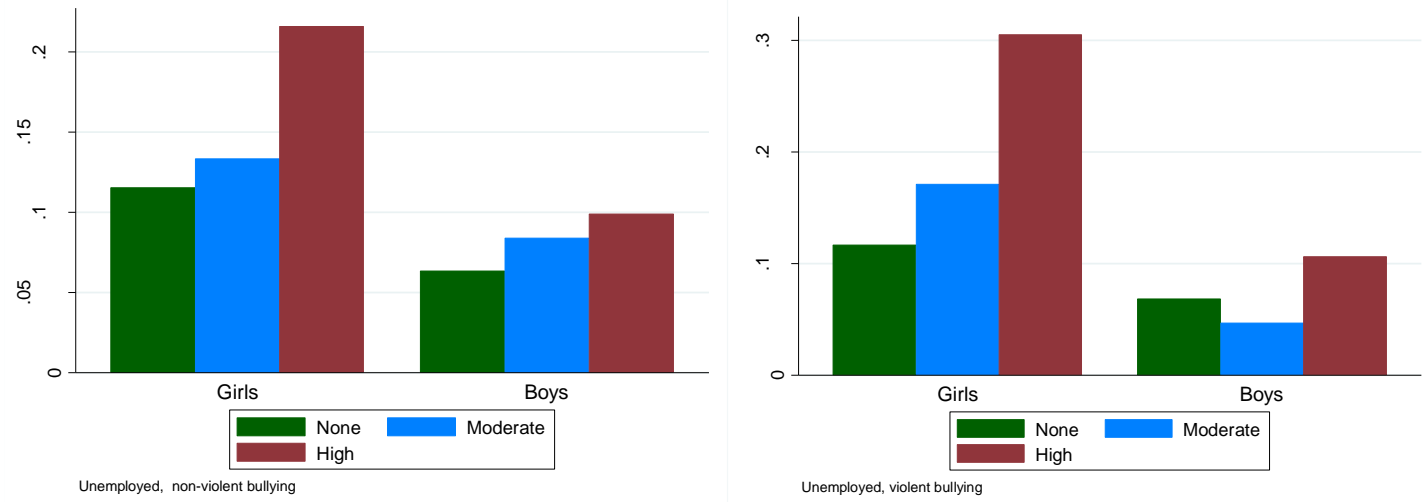

e) Weekly income - Non-violent and violent
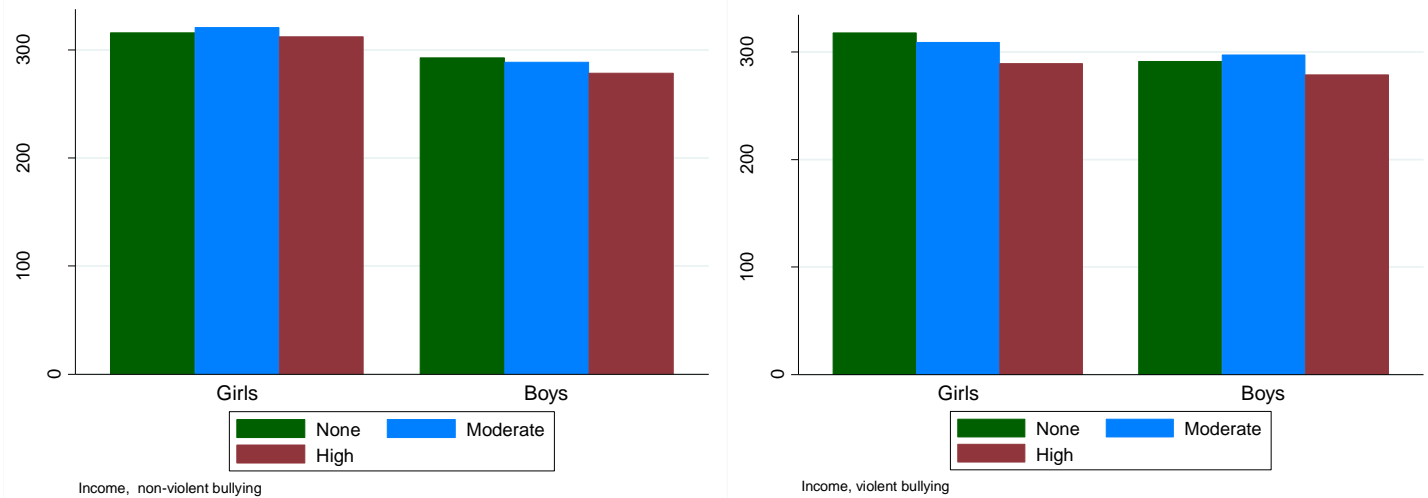

f) Mental health - Non-violent and violent
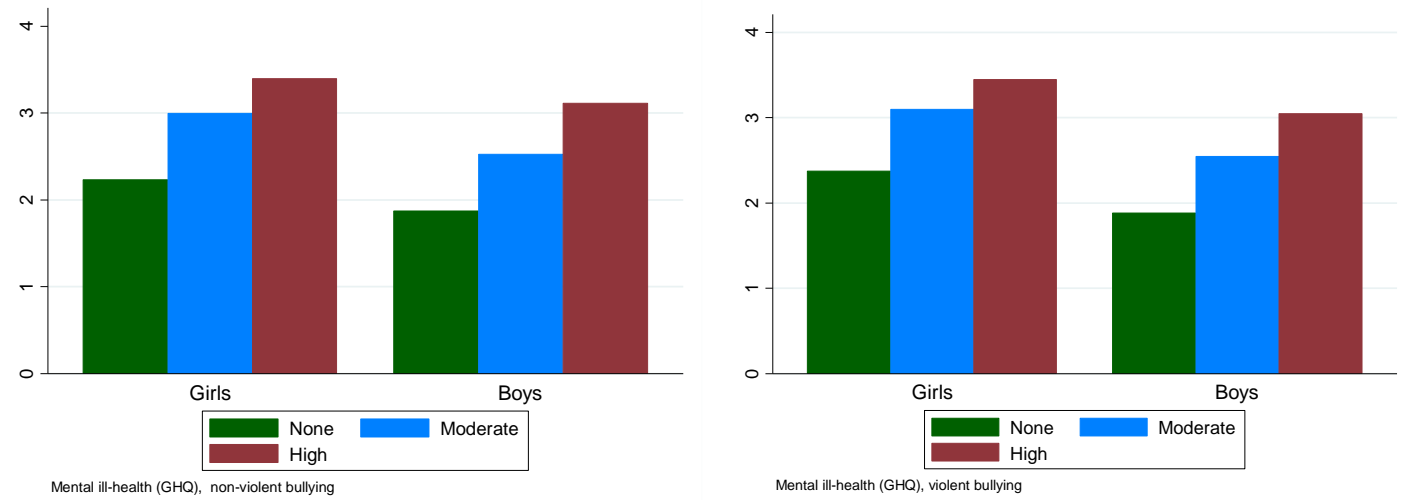

g) University degree - Non-violent and violent
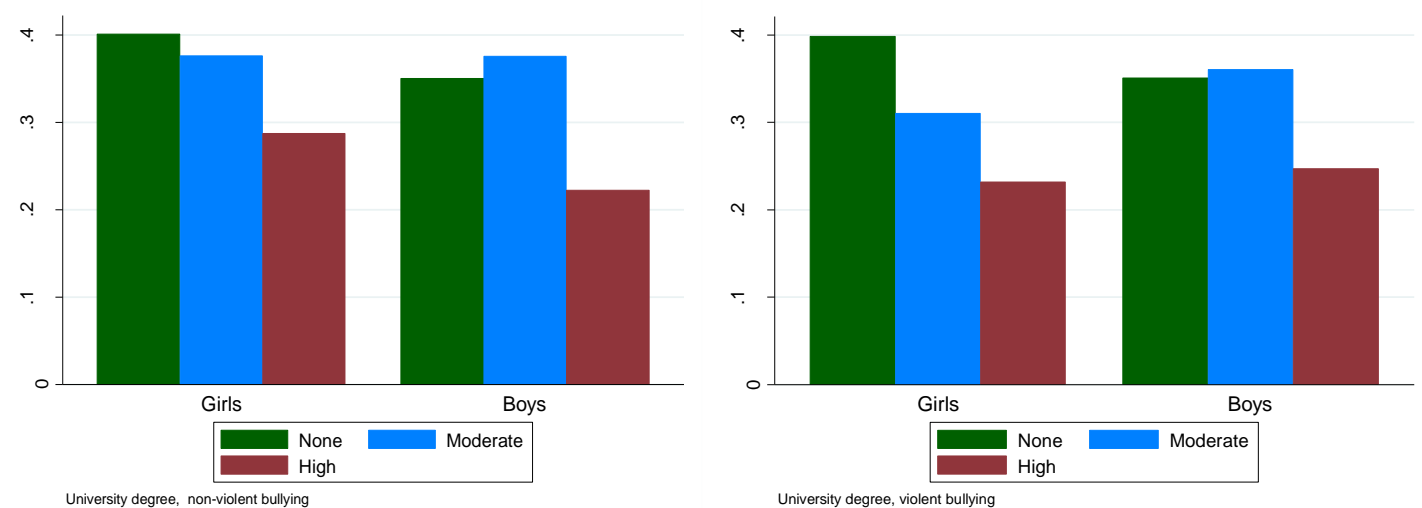


\section{WEB APPENDIX}

Web Appendix Table 1: $\quad$ Unweighted summary stats for bullying variables

\begin{tabular}{rccr} 
& Mean & SD & $\begin{array}{c}\text { Unweighted } \\
\text { N }\end{array}$ \\
\hline Parent report of type: & & & \\
Called names & 0.30 & 0.46 & 6,885 \\
Excluded from groups & 0.11 & 0.31 & 6,885 \\
Made to hand over money or items & 0.01 & 0.12 & 6,885 \\
Threatened with violence & 0.12 & 0.32 & 6,885 \\
Experienced violence & 0.10 & 0.30 & 6,885
\end{tabular}

Child report of type:

Called names

0.30

0.46

7,102

Excluded from groups

0.16

0.37

7,135

Made to hand over money or items

0.03

7,297

Threatened with violence

0.19

0.18

7,236

Experienced violence

0.16

7,250

Child report (factor)

$-0.07$

0.39

0.37

Parent report (factor)

$-0.09$

0.82

4,890

4,971

Web Appendix Figure 1: $\quad$ Histogram showing common support and balance of the matched sample. All observations are on the common support.

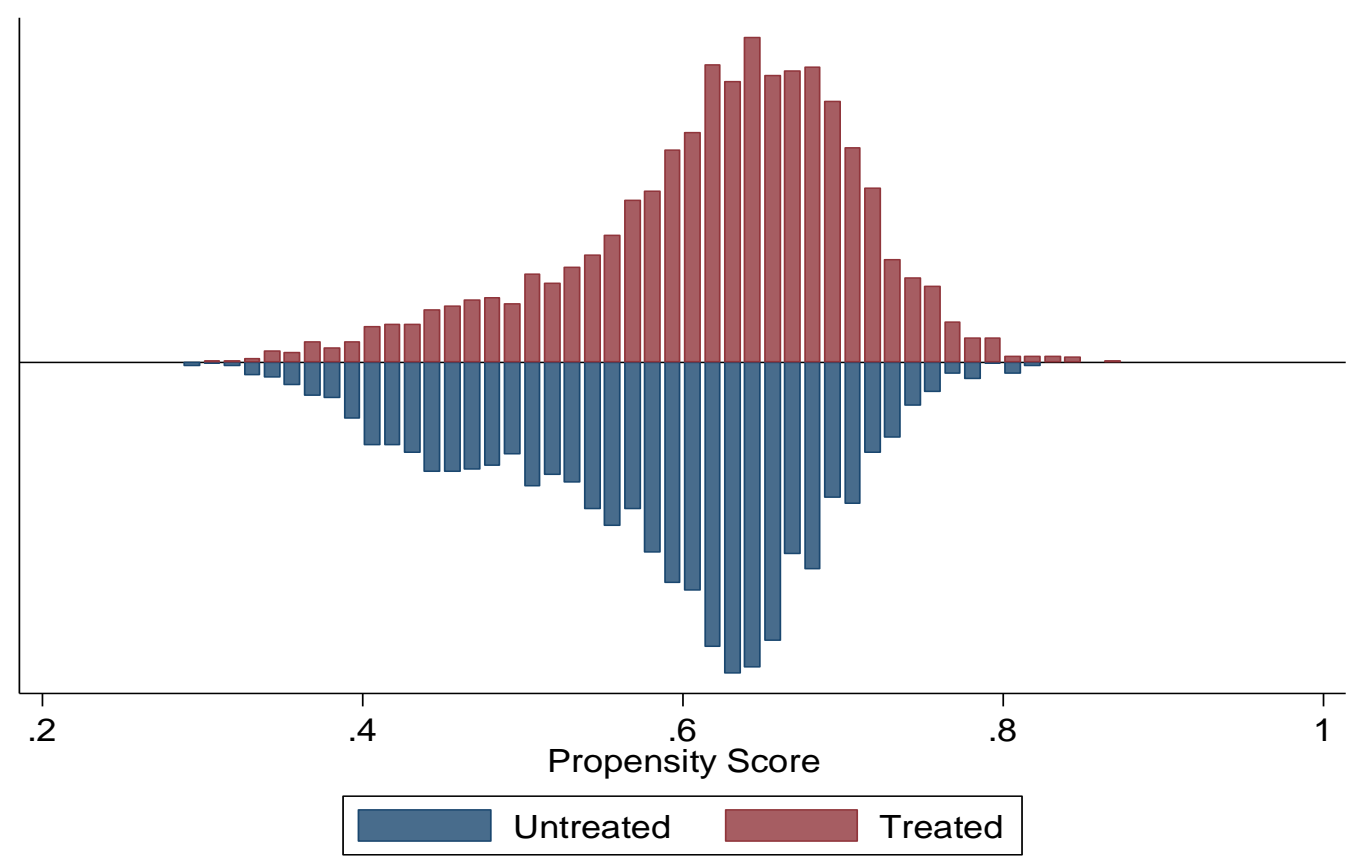


Web Appendix Figure 2: $\quad$ Plot summarizing the balance statistics comparing the unmatched and matched sample (from-psgraph-)
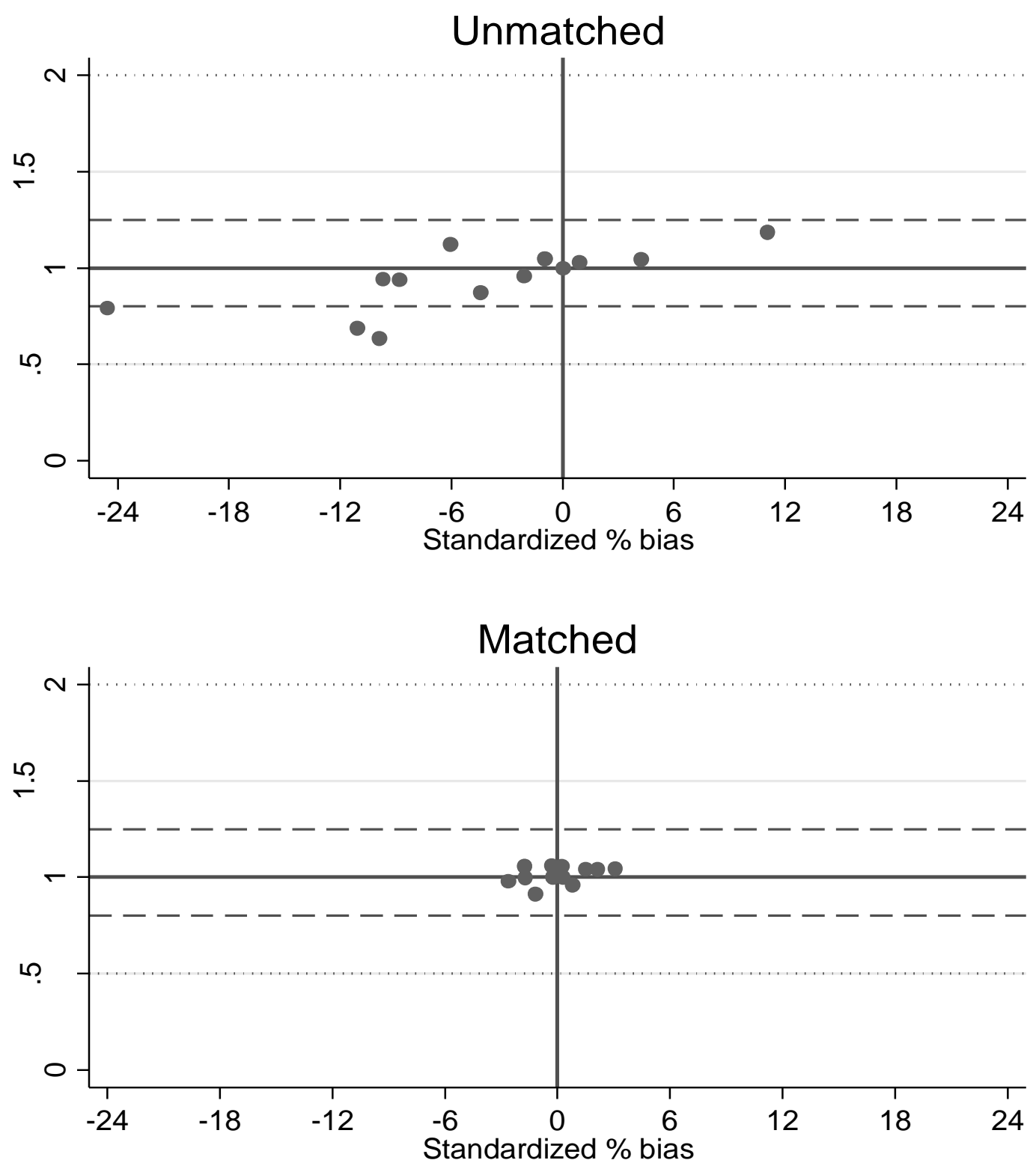
Web Appendix Table 2:

Multivariate distance matching

\begin{tabular}{lrrrrr} 
& ATT & std.err & $\mathrm{N}$ (control) & $\mathrm{N}$ (treated) & Total N \\
\hline & & & & & \\
5+ GCSE & -0.0452 & 0.0127 & 2,401 & 3,732 & 6,133 \\
Any A-levels? & -0.0322 & 0.0153 & 2,526 & 3,887 & 6,413 \\
Best 3 A-level points & -9.3701 & 3.9647 & 1,549 & 2,122 & 3,671 \\
& & & & & \\
ln(Income) & -0.0147 & 0.0048 & 2,526 & 3,887 & 6,413 \\
Has a university degree & -0.0081 & 0.0157 & 2,526 & 3,887 & 6,413 \\
Unemployed & 0.0260 & 0.0088 & 2,526 & 3,887 & 6,413 \\
Mental health & 1.0121 & 0.0903 & 2,417 & 3,745 & 6,162
\end{tabular}

Notes: ATT: Average Treatment Effect on the Treated; Std. err: Robust Abadie/Imbens standard errors. The covariates included are from Specification 2.

Web Appendix Table 3

Nearest neighbour propensity score matching

\begin{tabular}{lrrrrr} 
& ATT & std.err & $\mathrm{N}$ (control) & $\mathrm{N}$ (treated) & Total N \\
\hline & & & & & \\
5+ GCSE & -0.0377 & 0.0104 & 2,401 & 3,732 & 6,133 \\
Any A-levels? & -0.0379 & 0.0126 & 2,526 & 3,887 & 6,413 \\
Best 3 A-level points & -8.3539 & 3.3439 & 1,549 & 2,122 & 3,671 \\
& & & & & \\
ln(Income) & -0.0133 & 0.0046 & 2,526 & 3,887 & 6,413 \\
Has a degree & -0.0102 & 0.0125 & 2,526 & 3,887 & 6,413 \\
Unemployed & 0.0285 & 0.0078 & 2,526 & 3,887 & 6,413 \\
Mental health & 0.9584 & 0.0818 & 2,417 & 3,745 & 6,162
\end{tabular}

Notes: ATT: Average Treatment Effect on the Treated; Std. err: Robust Abadie/Imbens standard errors; $\mathrm{nn}=5$; caliper $=0.15$. The covariates included are from Specification 2. 
Web Appendix Table 4:

OLS and IV estimates of the effects of bullying (binary and continuous) on girls.

\begin{tabular}{|c|c|c|c|c|c|c|c|}
\hline Dependent Variable: & 5+ GCSE & $\begin{array}{l}\text { Any A- } \\
\text { levels }\end{array}$ & $\begin{array}{c}\text { Best } 3 \text { A-level } \\
\text { points }\end{array}$ & Ln(income) & $\begin{array}{l}\text { University } \\
\text { degree }\end{array}$ & Unemployed & Mental health \\
\hline \multicolumn{8}{|c|}{ (OLS) Binary treatment } \\
\hline$\beta$ & $-0.0355 * * *$ & $-0.0309 *$ & -4.522 & -0.00710 & $-0.0456 * * *$ & $0.0210^{*}$ & $1.019^{* * *}$ \\
\hline $\operatorname{se}(\beta)$ & $(0.0126)$ & $(0.0163)$ & $(4.970)$ & $(0.00478)$ & $(0.0174)$ & $(0.0118)$ & $(0.119)$ \\
\hline $\mathrm{N}$ & 3,416 & 3,570 & 2,085 & 3,570 & 3,570 & 3,570 & 3,436 \\
\hline $\begin{array}{l}\text { Gender diff. } \\
\text { p-value }\end{array}$ & 0.418 & 0.475 & 0.896 & 0.274 & 0.029 & 0.376 & 0.082 \\
\hline \multicolumn{8}{|c|}{ (OLS) Continuous treatment } \\
\hline$\beta$ & -0.0235 & -0.0165 & -4.299 & -0.00556 & $-0.0166^{*}$ & 0.0103 & $0.224 * * *$ \\
\hline $\operatorname{se}(\beta)$ & $(0.0143)$ & $(0.0113)$ & $(5.190)$ & $(0.00419)$ & $(0.00982)$ & $(0.0115)$ & $(0.0798)$ \\
\hline $\mathrm{N}$ & 2,430 & 2,437 & 1,544 & 2,437 & 2,437 & 2,437 & 2,359 \\
\hline $\begin{array}{l}\text { Gender diff. } \\
\text { p-value }\end{array}$ & 0.529 & 0.287 & 0.967 & 0.740 & 0.713 & 0.603 & 0.848 \\
\hline \multicolumn{8}{|c|}{ (IV) Continuous treatment } \\
\hline$\beta$ & -0.0374 & -0.0656 & -14.50 & $-0.0256^{*}$ & -0.0496 & 0.0108 & 0.324 \\
\hline $\operatorname{se}(\beta)$ & $(0.0340)$ & $(0.0428)$ & $(109.9)$ & $(0.0141)$ & $(0.0315)$ & $(0.0211)$ & $(0.215)$ \\
\hline $\mathrm{N}$ & 1,832 & 1,836 & 1,205 & 1,836 & 1,836 & 1,836 & 1,779 \\
\hline
\end{tabular}

Notes: Gender diff': the $\mathrm{p}$-value from a test for differences in the effect between the boys and girls subgroup. Robust standard errors, clustered by school, in parentheses. $* * * \mathrm{p}<0.01, * *$ $\mathrm{p}<0.05, * \mathrm{p}<0.10$. The covariates included are from Specification 2 . 
Web Appendix Table 5:

OLS and IV estimates of the effects of bullying on boys.

\begin{tabular}{|c|c|c|c|c|c|c|c|}
\hline Dependent Variable: & $5+\mathrm{GCSE}$ & Any A-levels & $\begin{array}{l}\text { Best } 3 \text { A- } \\
\text { level points }\end{array}$ & Ln(income) & $\begin{array}{l}\text { University } \\
\text { degree }\end{array}$ & Unemployed & $\begin{array}{l}\text { Mental } \\
\text { health }\end{array}$ \\
\hline \multicolumn{8}{|c|}{ (OLS) Binary treatment } \\
\hline$\beta$ & -0.0208 & -0.0201 & -6.808 & $-0.0108 *$ & 0.0313 & $0.0383 * * *$ & $0.660 * * *$ \\
\hline $\operatorname{se}(\beta)$ & $(0.0161)$ & $(0.0183)$ & $(5.830)$ & $(0.00592)$ & $(0.0201)$ & $(0.00972)$ & $(0.130)$ \\
\hline $\mathrm{N}$ & 2,717 & 2,843 & 1,586 & 2,843 & 2,843 & 2,843 & 2,726 \\
\hline \multicolumn{8}{|c|}{ (OLS) Continuous treatment } \\
\hline$\beta$ & -0.00599 & $-0.0317 * * *$ & -1.501 & -0.00549 & $-0.0192 *$ & 0.00912 & $0.309 * * *$ \\
\hline $\operatorname{se}(\beta)$ & $(0.00857)$ & $(0.0113)$ & $(4.427)$ & $(0.00351)$ & $(0.0104)$ & $(0.00632)$ & $(0.0848)$ \\
\hline $\mathrm{N}$ & 2,020 & 2,027 & 1,236 & 2,027 & 2,027 & 2,027 & 1,948 \\
\hline \multicolumn{8}{|c|}{ (IV) Continuous treatment } \\
\hline$\beta$ & -0.00861 & -0.0406 & -17.23 & -0.0120 & $-0.0662 * *$ & 0.0374 & $0.964 * * *$ \\
\hline $\operatorname{se}(\beta)$ & $(0.0251)$ & $(0.0359)$ & $(11.53)$ & $(0.00812)$ & $(0.0291)$ & $(0.0261)$ & $(0.366)$ \\
\hline $\mathrm{N}$ & 1,612 & 1,619 & 1,004 & 1,619 & 1,619 & 1,619 & 1,558 \\
\hline
\end{tabular}

Notes: Robust standard errors, clustered by school, in parentheses. *** $\mathrm{p}<0.01, * * \mathrm{p}<0.05, * \mathrm{p}<0.10$. The covariates included are from Specification 2 
Web Appendix Table 6:

\begin{tabular}{|c|c|c|c|c|c|c|c|}
\hline $\begin{array}{l}\text { Dependent } \\
\text { Variable: }\end{array}$ & $\begin{array}{c}5+ \\
\text { GCSE }\end{array}$ & $\begin{array}{c}\text { Any A- } \\
\text { levels }\end{array}$ & $\begin{array}{l}\text { Best } 3 \\
\text { A-level } \\
\text { points }\end{array}$ & $\begin{array}{c}\text { University } \\
\text { degree }\end{array}$ & Ln(income) & Unemployed & $\begin{array}{l}\text { Mental } \\
\text { health }\end{array}$ \\
\hline No bullying & ref & ref & ref & ref & ref & ref & ref \\
\hline $\begin{array}{r}\beta \text { No non- } \\
\text { violent } / \text { low } \\
\text { violent }\end{array}$ & -0.004 & 0.039 & -18.842 & -0.022 & -0.0090 & -0.0389 & 0.4532 \\
\hline s.e. & 0.026 & 0.031 & 10.233 & 0.031 & 0.0107 & 0.0131 & 0.2187 \\
\hline $\begin{array}{r}\beta \text { No non- } \\
\text { violent / high } \\
\text { violent }\end{array}$ & -0.022 & -0.018 & -20.724 & -0.037 & -0.0289 & -0.0057 & 0.4176 \\
\hline s.e. & 0.048 & 0.054 & 25.542 & 0.053 & 0.0188 & 0.0276 & 0.4387 \\
\hline $\begin{array}{r}\beta \text { Low non- } \\
\text { violent / no } \\
\text { violent }\end{array}$ & -0.047 & 0.035 & 5.847 & 0.089 & -0.0115 & 0.0285 & 0.5870 \\
\hline s.e. & 0.024 & 0.027 & 5.295 & 0.030 & 0.0106 & 0.0187 & 0.2035 \\
\hline $\begin{array}{r}\beta \text { Low non- } \\
\text { violent } / \text { low } \\
\text { violent }\end{array}$ & -0.066 & -0.012 & 7.602 & 0.030 & 0.0070 & 0.0223 & 0.7052 \\
\hline s.e. & 0.033 & 0.038 & 7.526 & 0.039 & 0.0128 & 0.0236 & 0.2893 \\
\hline $\begin{array}{r}\beta \text { Low non- } \\
\text { violent / high } \\
\text { violent }\end{array}$ & -0.111 & -0.058 & -3.547 & -0.035 & -0.0456 & -0.0026 & 0.9149 \\
\hline s.e. & 0.037 & 0.043 & 19.371 & 0.050 & 0.0168 & 0.0233 & 0.3567 \\
\hline $\begin{array}{r}\beta \text { High non- } \\
\text { violent } / \text { no } \\
\text { violent }\end{array}$ & -0.162 & -0.106 & 14.500 & -0.046 & -0.0099 & 0.0183 & 0.6867 \\
\hline s.e. & 0.039 & 0.041 & 11.371 & 0.049 & 0.0170 & 0.0239 & 0.2934 \\
\hline $\begin{array}{r}\beta \text { High non- } \\
\text { violent } / \text { low } \\
\text { violent }\end{array}$ & -0.005 & 0.000 & -22.610 & 0.035 & -0.0205 & 0.0248 & 0.8606 \\
\hline s.e. & 0.042 & 0.045 & 11.567 & 0.048 & 0.0141 & 0.0298 & 0.3092 \\
\hline $\begin{array}{r}\beta \text { High non- } \\
\text { violent / high } \\
\text { violent }\end{array}$ & -0.116 & -0.105 & 6.545 & -0.050 & -0.0370 & 0.0791 & 1.3709 \\
\hline s.e. & 0.034 & 0.041 & 10.933 & 0.043 & 0.0133 & 0.0281 & 0.2736 \\
\hline $\mathrm{N}$ & 5,924 & 6,650 & 3,531 & 6,650 & 6,650 & 6,650 & 6,378 \\
\hline
\end{tabular}


Web Appendix Table 7: $\quad$ GMM estimates of the effects of bullying separately by gender

\begin{tabular}{|c|c|c|c|c|c|c|c|}
\hline $\begin{array}{l}\text { Dependent } \\
\text { Variable: }\end{array}$ & $5+\mathrm{GCSE}$ & Any A-levels & $\begin{array}{l}\text { Best } 3 \text { A- } \\
\text { level points }\end{array}$ & Ln(income) & $\begin{array}{c}\text { University } \\
\text { degree }\end{array}$ & Unemployed & $\begin{array}{l}\text { Mental } \\
\text { health }\end{array}$ \\
\hline \multicolumn{8}{|l|}{ Girls } \\
\hline$\beta$ & -0.0401 & -0.0659 & -18.45 & $-0.0254^{*}$ & -0.0499 & 0.0104 & 0.326 \\
\hline $\operatorname{se}(\beta)$ & $(0.0335)$ & $(0.0417)$ & (108.3) & $(0.0136)$ & $(0.0311)$ & $(0.0210)$ & $(0.213)$ \\
\hline $\mathrm{N}$ & 1,728 & 1,732 & 1,069 & 1,732 & 1,732 & 1,732 & 1,672 \\
\hline \multicolumn{8}{|l|}{ Boys } \\
\hline$\beta$ & -0.00849 & -0.0413 & $-18.76^{*}$ & -0.0110 & $-0.0651 * *$ & 0.0371 & $0.961^{* * * *}$ \\
\hline $\operatorname{se}(\beta)$ & $(0.0247)$ & $(0.0353)$ & (11.36) & $(0.00802)$ & $(0.0286)$ & $(0.0258)$ & $(0.361)$ \\
\hline $\mathrm{N}$ & 1,497 & 1,508 & 857 & 1,508 & 1,508 & 1,508 & 1,437 \\
\hline
\end{tabular}

Notes: Robust standard errors, clustered by school, in parentheses. ${ }^{* * *} \mathrm{p}<0.01, * * \mathrm{p}<0.05,{ }^{*} \mathrm{p}<0.10$. The covariates included are from Specification 2. 